\title{
Selective Self-Organization of Guest Molecules in Self-Assembled Molecular Boxes
}

\author{
Jessica M. C. A. Kerckhoffs, ${ }^{\dagger}$ Mattijs G. J. ten Cate, ${ }^{\dagger}$ Miguel A. Mateos-Timoneda,${ }^{\dagger}$ \\ Fijs W. B. van Leeuwen, ${ }^{\dagger}$ Bianca Snellink-Ruël, ${ }^{\dagger}$ Anthony L. Spek, ${ }^{\dagger}$ \\ Huub Kooijman, ${ }^{\ddagger}$ Mercedes Crego-Calama, ${ }^{*}$, and David N. Reinhoudt ${ }^{*}, \dagger$ \\ Contribution from the Laboratory of Supramolecular Chemistry and Technology, \\ $\mathrm{MESA}^{+}$Institute for Nanotechnology, University of Twente, P.O. Box 217, 7500 AE Enschede, \\ The Netherlands, and Crystal and Structural Chemistry, Bijvoet Center for Biomolecular \\ Research, Utrecht University, Padualaan 8, 3584 CH Utrecht, The Netherlands
}

Received June 6, 2005; E-mail: m.cregocalama@utwente.nl

\begin{abstract}
This article describes the synthesis and binding properties of highly selective noncovalent molecular receptors $\mathbf{1}_{3} \cdot(\mathrm{DEB})_{6}$ and $\mathbf{3}_{3} \cdot(\mathrm{DEB})_{6}$ for different hydroxyl functionalized anthraquinones 2 . These receptors are formed by the self-assembly of three calix[4]arene dimelamine derivative molecules (1 or 3) and six diethylbarbiturate (DEB) molecules to give $\mathbf{1}_{3} \cdot(\mathrm{DEB})_{6}$ or $\mathbf{3}_{3} \cdot(\mathrm{DEB})_{6}$. Encapsulation of 2 occurs in a highly organized manner; that is, a noncovalent hydrogen-bonded trimer of $\mathbf{2}$ is formed within the hydrogenbonded receptors $\mathbf{1}_{3} \cdot(\mathrm{DEB})_{6}$ and $\mathbf{3}_{3} \cdot(\mathrm{DEB})_{6}$. Both receptors $\mathbf{1}_{3} \cdot(\mathrm{DEB})_{6}$ and $\mathbf{3}_{3} \cdot(\mathrm{DEB})_{6}$ change conformation from staggered to eclipsed upon complexation to afford a better fit for the $2_{3}$ trimer. The receptor selectivity toward different anthraquinone derivatives 2 has been studied using ${ }^{1} \mathrm{H}$ NMR spectroscopy, $\mathrm{X}$-ray crystallography, UV spectroscopy, and isothermal microcalorimetry (ITC). The $\pi-\pi$ stacking between the electron-deficient center ring of the anthraquinone derivatives $2 \mathbf{a}-\mathbf{c}$ and $\mathbf{2 e}-\mathbf{g}$ and the relatively electronpoor melamine units of the receptor is the driving force for the encapsulation of the guest molecules. The selectivity of the hydrogen-bonded host for the anthraquinone derivatives is the result of steric interactions between the guest molecules and the calix[4]arene aromatic rings of the host.
\end{abstract}

\section{Introduction}

One of the ambitious goals in supramolecular chemistry is the self-assembly of synthetic building blocks into highly organized structures. ${ }^{1}$ Nature provides the perfect example for this approach; that is, highly complex functional structures, such as cells and viruses, are obtained by self-assembly, which allows errors to be minimized and/or spontaneously corrected. ${ }^{2,3}$ However, the control and organizational complexity found in these biological enclosures is still far beyond the synthetic abilities of chemists, ${ }^{4}$ although beautiful examples of selfassembled molecular containers have been reported. ${ }^{5-11}$ The use

\footnotetext{
$\dagger$ University of Twente.
}

$\doteqdot$ Utrecht University.

(1) (a) Greig, L. M.; Philp, D. Chem. Soc. Rev. 2001, 30, 287-302. (b) Reinhoudt, D. N.; Crego-Calama, M. Science 2002, 295, 2403-2407.

(2) Lindsey, J. S. New J. Chem. 1991, 15, 153-180.

(3) Stryer, L. Biochemistry, 4th ed.; W. H. Freeman and Company: New York, 1995 .

(4) Fiammengo, R.; Crego-Calama, M.; Reinhoudt, D. N. Curr. Opin. Chem. Biol. 2001, 5, 660-673.

(5) Chen, J.; Körner, S.; Craig, S. L.; Rudkevich, D. M.; Rebek, J., Jr. Nature 2002, 415, 385-386.

(6) Rincon, A. M.; Prados, P.; de Mendoza, J. J. Am. Chem. Soc. 2001, 123 3493-3498

(7) Vysotsky, M. O.; Thondorf, I.; Böhmer, V. Angew. Chem., Int. Ed. 2000 , 39, 1264-1267.

(8) Umemoto, K.; Tsukui, H.; Kusukawa, T.; Biradha, K.; Fuijta, M. Angew. Chem., Int. Ed. 2001, 40, 2620-2622.

(9) Jacopozzi, P.; Dalcanale, E. Angew. Chem., Int. Ed. Engl. 1997, 36, 613615

10.1021/ja0536973 CCC: $\$ 30.25$ @ 2005 American Chemical Society of multiple hydrogen bonds for the formation of these containers is widely studied..$^{5-7}$ Alternatively, metal ions ${ }^{8,9}$ and multiple ionic interactions ${ }^{10,11}$ are used for the construction of selfassembled capsules. Molecular capsules have many potential applications, ranging from drug delivery and molecular recognition to molecular reaction chambers for catalysis and stabilization of reactive intermediates. ${ }^{12-15}$

Encapsulation of guest molecules in this type of synthetic self-assembled receptors is being studied intensively. ${ }^{16-18}$ Noncovalent synthesis facilitates the encapsulation dramatically by the ability of the capsule to (re)assemble around the guest molecules, while covalent capsules ${ }^{19,20}$ should contain a "door"

(10) Corbellini, F.; Fiammengo, R.; Timmerman, P.; Crego-Calama, M.; Versluis, K.; Heck, A. J. R.; Luyten, I.; Reinhoudt, D. N. J. Am. Chem. Soc. 2002, $124,6569-6575$.

(11) Fiammengo, R.; Wojciechowski, K.; Crego-Calama, M.; Timmerman, P. Figoli, A.; Wessling, M.; Reinhoudt, D. N. Org. Lett. 2003, 5, 3367-3370.

(12) Kang, J.; Rebek, J., Jr. Nature 1997, 385, 50-52.

(13) Kang, J.; Santamaría, J.; Hilmersson, G.; Rebek, J., Jr. J. Am. Chem. Soc. 1998, 120, 7389-7390.

(14) Kang, J.; Hilmersson, G.; Santamaría, J.; Rebek, J., Jr. J. Am. Chem. Soc 1998, 120, 3650-3656.

(15) Schalley, C. A Adv Mater 1999, $11,1535-1537$.

(16) Conn, M. M.; Rebek, J., Jr. Chem. Rev. 1997, 97, 1647-1668.

(17) Hof, F.; Craig, S. L.; Nuckolls, C.; Rebek, J., Jr. Angew. Chem., Int. Ed. 2002, 41, 1488-1508 and references therein.

(18) Schalley, C. A. Angew. Chem., Int. Ed. 2002, 41, 1513-1515.

(19) Chopra, N.; Sherman, J. C. Angew. Chem. Int. Ed 1999, 38, 1955-1957.

(20) Cram, D. J.; Karbach, S.; Kim, Y. H.; Baczynskyj, L.; Kalleymeyn, G. W. J. Am. Chem. Soc. 1985, 107, 2575-2576. 
Chart 1. Molecular Representation of Compounds $\mathbf{1} \mathbf{a}, \mathbf{b}$ and $\mathbf{3 a}, \mathbf{b}$, The Corresponding Hydrogen-Bonded Assemblies $\mathbf{1 , 3} 3^{\cdot} \cdot(\mathrm{DEB} / \mathrm{CYA})_{6}$ and Their Top and Side View Schematic Representations: The Molecular Structures of Guests $\mathbf{2 a}-\mathbf{h}$ and $\mathbf{4}$ Are Also Depicted

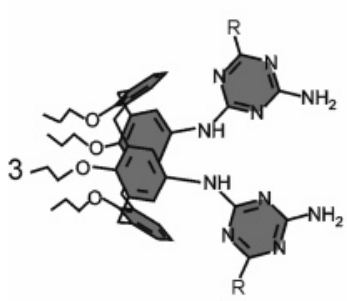

1a $\mathrm{R}=\mathrm{NH}\left(\mathrm{CH}_{2}\right)_{3} \mathrm{CH}_{3}$ 1b $\mathrm{R}=\mathrm{NH}\left(\mathrm{CH}_{2}\right)_{6} \mathrm{CH}=\mathrm{CH}_{2}$ 3a $\mathrm{R}=\mathrm{NH}-(\mathrm{R})-\mathrm{CH}\left(\mathrm{C}_{6} \mathrm{H}_{5}\right) \mathrm{CH}_{3}$ 3b $\mathrm{R}=\mathrm{NH}-(\mathrm{S})-\mathrm{CH}\left(\mathrm{C}_{6} \mathrm{H}_{5}\right) \mathrm{CH}_{3}$
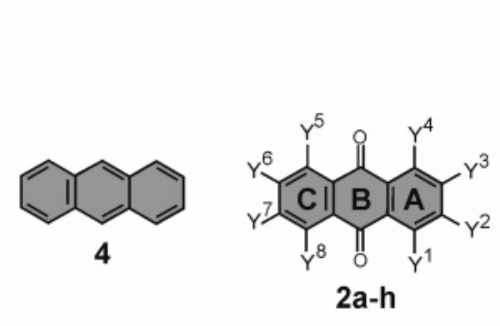

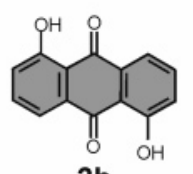

$2 \mathrm{~b}$

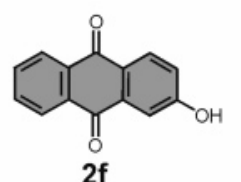

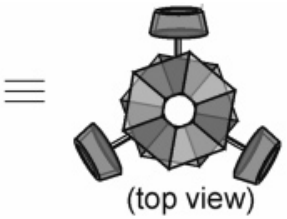

(top view)

\section{DEB $\mathrm{X}=\mathrm{C}\left(\mathrm{CH}_{2} \mathrm{CH}_{3}\right)_{2}$} $\mathrm{BuCYAX}=\mathrm{N}\left(\mathrm{CH}_{2}\right)_{3} \mathrm{CH}_{3}$

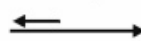

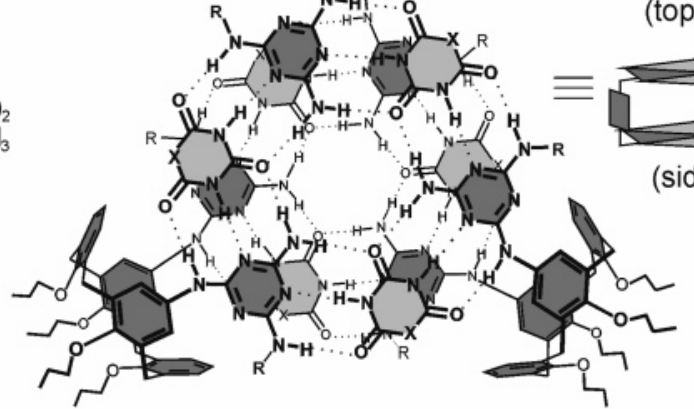

$\mathbf{1}_{3} \cdot(\mathrm{DEB} / \mathrm{CYA})_{6}$ $\mathbf{3}_{3} \cdot(\mathrm{DEB} / \mathrm{CYA})_{6}$ through which the guest molecules can enter the capsule. Entrapment of guest molecules in noncovalent molecular containers is mostly achieved by the steric constraints exerted by rigid preorganized building blocks. ${ }^{21}$ In literature, there are only a few examples known wherein self-organization of guest molecules in the molecular capsule occurs via noncovalent interactions..$^{22-25}$ Our group has recently shown the first example of such a system, wherein the self-organization of both guest and host is based on the same type of noncovalent interactions (i.e., hydrogen bonding). ${ }^{26}$

Here, the highly organized encapsulation and selectivity toward anthraquinone derivatives $\mathbf{2} \mathbf{a}-\mathbf{h}$ (Chart 1) by the noncovalent molecular box $\mathbf{1 a}_{3} \cdot(\mathrm{DEB})_{6}$ is described. This host assembly is formed by mixing calix[4]arene dimelamine 1a and diethyl barbituric acid (DEB) in a ratio of 3:6 in apolar solvents. To determine the selectivity of this receptor, a range of very similar anthraquinone derivatives $\mathbf{2} \mathbf{a}-\mathbf{h}$, differing only in the number and position of $\mathrm{OH}$ groups in the anthraquinone skeleton, have been chosen. ${ }^{1} \mathrm{H}$ NMR spectroscopy, X-ray crystallography, UV-vis spectroscopy, and isothermal microcalorimetry (ITC), used to study the affinity of this receptor,

(21) Ziegler, M.; Brumaghim, J. L.; Raymond, K. N. Angew. Chem., Int. Ed. 2000, 39, 4119-4121.

(22) Kusukawa, T.; Fujita, M. J. Am. Chem. Soc. 1999, 121, 1397-1398.

(23) Kang, J.; Rebek, J., Jr. Nature 1996, 382, 239-241.

(24) Heinz, T.; Rudkevich, D. M.; Rebek, J., Jr. Nature 1998, 394, 764766.

25) Kusukawa, T.; Fujita, M. J. Am. Chem. Soc. 2002, 124, 13576-13582.

(26) Kerckhoffs, J. M. C. A.; van Leeuwen, F. W. B.; Spek, A. L.; Kooijman, H.; Crego-Calama, M.; Reinhoudt, D. N. Angew. Chem., Int. Ed. 2003, $42,5717-5722$ show that this receptor is very sensitive toward small structural variations of the guest molecule. The encapsulation of $\mathbf{2 a}$ by the chiral receptors $\mathbf{3 a}-\mathbf{b}_{3} \cdot(\mathrm{DEB})_{6}$ shows the same complexation behavior as the racemic receptor $\mathbf{1 a}_{3} \cdot(\mathrm{DEB})_{6}$.

\section{Results and Discussion}

Assemblies $1, \mathbf{3}_{3} \cdot(\mathrm{DEB} / \mathrm{CYA})_{6}$ are formed upon mixing calix[4] arene dimelamines $\mathbf{1 , 3}$ and DEB or cyanurate derivatives in a 1:2 ratio in apolar solvents, such as chloroform, toluene, or benzene. ${ }^{27,28}$ These assemblies are held together by the formation of 36 hydrogen bonds, and therefore, they are thermodynamically stable. The top and bottom of these molecular boxes comprise cyclic hydrogen-bonded rosette motifs, with the three calix[4]arene units acting as side walls.

Previous studies in our group have shown that the addition of 4 equiv of alizarin (2a) to the hydrogen-bonded receptor $\mathbf{1 a}_{3}$. $(\mathrm{DEB})_{6}\left(1.0 \mathrm{mM}\right.$ in $\left.\mathrm{CDCl}_{3}\right)$ results in the encapsulation of a hydrogen-bonded alizarine trimer $\left(\mathbf{2}_{3}\right)$ between the two rosette layers of the receptor. ${ }^{26} \mathrm{X}$-ray analysis and 2D ${ }^{1} \mathrm{H}$ NMR (2D DQF ${ }^{29}$ TOCSY, ${ }^{30}$ and NOESY ${ }^{31}$ ) experiments were used to show unequivocally the geometry of the complex $\mathbf{1 a}_{3} \cdot(\mathrm{DEB})_{6} \cdot$

(27) Timmerman, P.; Vreekamp, R. H.; Hulst, R.; Verboom, W.; Reinhoudt, D. N.; Rissanen, K.; Udachin, K. A.; Ripmeester, J. Chem.-Eur. J. 1997 3, $1823-1832$.

(28) Vreekamp, R. H.; van Duynhoven, J. P. M.; Hubert, M.; Verboom, W.; Reinhoudt, D. N. Angew. Chem., Int. Ed. 1996, 35, 1215-1218.

(29) Rance, M.; Sørensen, O. W.; Bodenhausen, G.; Wagner, G.; Ernst, R. R.; Wütrich, K. Biochem. Biophys. Res. Commun. 1983, 117, 479-485.

(30) Bax, A.; Davis, D. G. J. Magn. Reson. 1985, 65, 355-360.

(31) Jeener, J.; Meier, B. H.; Bachman, P.; Ernst, R. R. J. Chem. Phys. 1979, $71,4546-4569$. 
(a)

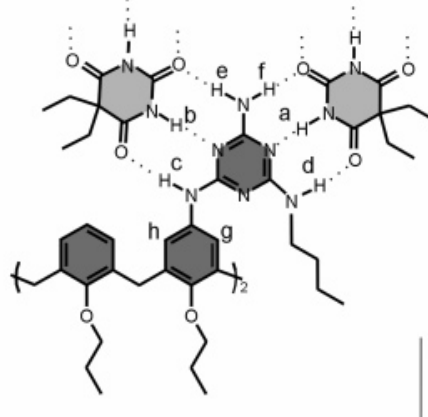

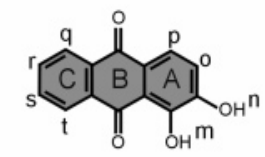

2a (alizarin)

(b)

(c)

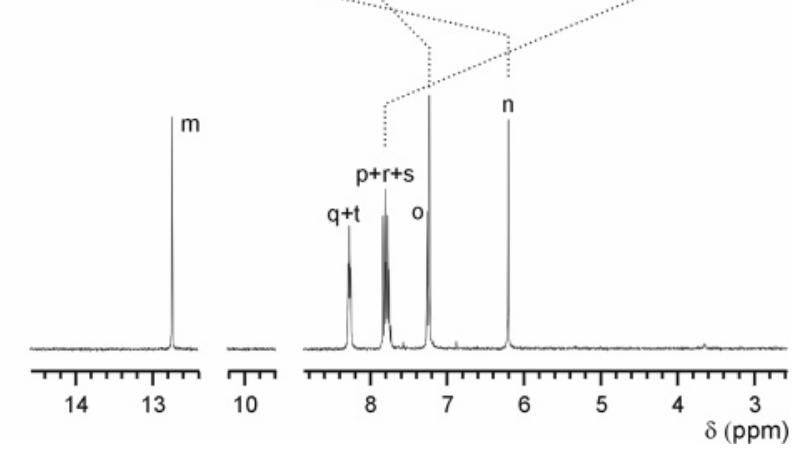

Figure 1. Part of the ${ }^{1} \mathrm{H}$ NMR spectra $\left(400 \mathrm{MHz}, \mathrm{CDCl}_{3}\right)$ of (a) receptor $1 \mathbf{a}_{3} \cdot(\mathrm{DEB})_{6},(\mathrm{~b})$ complex $\mathbf{1}_{3} \cdot(\mathrm{DEB})_{6} \cdot \mathbf{2}_{3}$, and (c) guest molecule 2a. The signals corresponding to free $\mathbf{2 a}$ are marked with $*$.

$\mathbf{2} \mathbf{a}_{3}$. Specifically, these studies revealed that the 3.28-3.88 ppm upfield shifts of the aromatic protons $\mathrm{H}_{\mathrm{r}}, \mathrm{H}_{\mathrm{s}}$, and $\mathrm{H}_{\mathrm{t}}$ of $\mathbf{2 a}$ (ring $\mathrm{C}$, see Figure 1) are due to the inclusion of the aromatic ring $\mathrm{C}$ in the calix[4]arene cone. ${ }^{32}$ Additionally, almost all of the signals from the receptor $\mathbf{1 a}_{3} \cdot(\mathrm{DEB})_{6}$ are also shifted upon complexation $\left(-0.58 \mathrm{ppm}\left(\mathrm{H}_{\mathrm{a}}\right) ;-0.30 \mathrm{ppm}\left(\mathrm{H}_{\mathrm{b}}\right) ;-0.44 \mathrm{ppm}\left(\mathrm{H}_{\mathrm{c}}\right) ; 0.13 \mathrm{ppm}\right.$ $\left(\mathrm{H}_{\mathrm{d}}\right) ;-0.71 \mathrm{ppm}\left(\mathrm{H}_{\mathrm{e}}\right) ;-0.84 \mathrm{ppm}\left(\mathrm{H}_{\mathrm{f}}\right)$, Figure 1). The ${ }^{1} \mathrm{H}$ NMR studies showed also the slow exchange between free $\mathbf{2 a}$ and the complexed guest in $\mathbf{1 a}_{3} \cdot(\mathrm{DEB})_{6} \cdot \mathbf{2} \mathbf{a}_{3}$ on the NMR time scale.

The crystal structure ${ }^{26}$ revealed that the intermolecular separation between the rosette layers increases from 3.2-3.5 $5^{27}$ to $6.4-6.9 \AA$ upon encapsulation of the alizarin trimer. The

(32) Saito, S.; Nuckolls, C.; Rebek, J., Jr. J. Am. Chem. Soc. 2000, 122, $9628-$ 9630 .

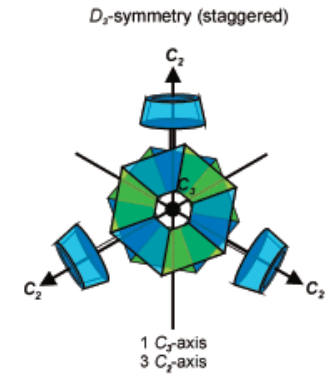

(b)

$C_{5}$-symmetry (staggered)

(c)

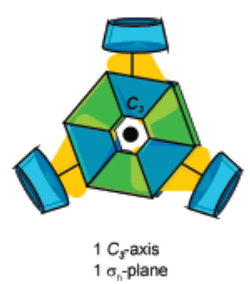

$C_{10}$-symmetry (eclipsed)

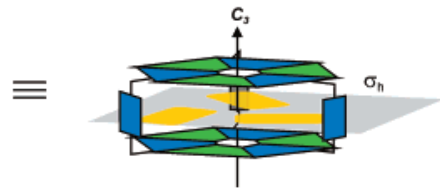

Figure 2. Graphical representation of the symmetry groups for the (a) assembly $1 \mathbf{a}_{3} \cdot(\mathrm{DEB})_{6}\left(D_{3}\right)$, (b) assembly $\mathbf{1 a}_{3} \cdot(\mathrm{DEB})_{6} \cdot \mathbf{2} \mathbf{a}_{3}\left(C_{3}\right)$, and (c) assembly $\mathbf{1} \mathbf{a}_{3} \cdot(\mathrm{DEB})_{6} \cdot \mathbf{2} \mathbf{a}_{3}$ (top and side view) $\left(C_{3 h}\right)$. (Rectangular figures denote the alizarin guest molecules.)

$\mathrm{O} \cdots \mathrm{O}$ distance (between the carbonyl of one guest molecule and the hydroxyl of the adjacent guest molecule) in the hydrogen-bonded network forming the $\mathbf{2} \mathbf{a}_{3}$ trimer is $2.7 \AA$, which is only found for $\mathrm{O} \cdots \mathrm{O}$ contact when there is a hydrogen bond.

On the other hand, the X-ray analysis showed that the two melamines of one calix[4]arene are in a parallel orientation (Figure 2) after encapsulation of the $\mathbf{2} \mathbf{a}_{3}$ trimer, while before the encapsulation, the two melamines of one calix[4]arene are in an antiparallel (staggered) orientation, which has also been confirmed by X-ray crystallography. ${ }^{27}$

In the work described in this paper, we have extended the study of the symmetry of the complex $\mathbf{1} \mathbf{a}_{3} \cdot(\mathrm{DEB})_{6} \cdot \mathbf{2} \mathbf{a}_{3}$ to prove that the molecular twist experienced by this receptor occurs undoubtedly also in solution.

$\mathrm{X}$-ray analysis showed that the complexation of $\mathbf{2} \mathbf{a}_{3}$ in the double rosette $1 \mathbf{a}_{3} \cdot(\mathrm{DEB})_{6}$ breaks the $D_{3}$ symmetry $^{33}$ (Figure 2) and gives the complex $\mathbf{1 a}_{3} \cdot(\mathrm{DEB})_{6} \cdot \mathbf{2} \mathbf{a}_{3}$ with local $C_{3 h}$ symmetry. The $D_{3}$ symmetrical structure has one $C_{3}$-axis (perpendicular to the plane of the page) and three $C_{2}$-axes perpendicular to the $C_{3}$-axis. For the $D_{3}$ isomer, two signals for the $\mathrm{NH}_{\mathrm{DEB}}$ protons $\mathrm{H}_{\mathrm{a}}$ and $\mathrm{H}_{\mathrm{b}}$ (see Figure 1 for the assignment of the protons) between 15 and $12 \mathrm{ppm}$ are expected because the three substituents on the dimelamines render these $\mathrm{NH}_{\text {DEB }}$ protons nonequivalent in the assembly. The two rosette layers are interconverted via a $C_{2}$-axis, rendering the protons in one rosette layer homotopic compared to the protons in the other rosette layer and giving identical resonances in the spectrum. Encapsulation of the trimer $\mathbf{2} \mathbf{a}_{3}$ in the staggered conformation would result in a structure with a $C_{3}$-axis but lacking the three $C_{2}$-axes, leading to four signals for the $\mathrm{NH}_{\mathrm{DEB}}$ protons, two for each rosette. However, because only two signals for these protons were observed in the ${ }^{1} \mathrm{H}$ NMR spectrum (see Figure 1), a horizontal plane of symmetry should be present, making the two rosette layers enantiotopic and giving the same $\mathrm{NH}_{\text {DEB }}$ resonances in the NMR spectrum. Consequently, the presence of the horizontal symmetry plane $\left(\sigma_{\mathrm{h}}\right)$ between the two

(33) Prins, L. J.; Timmerman, P.; Reinhoudt, D. N. Pure Appl. Chem. 1998, 70, 1459-1468. 
(a)

Staggered Rosette $\left(D_{3}\right)$

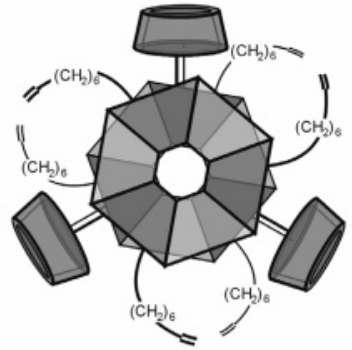

$1 \mathbf{b}_{3} \cdot(\mathrm{DEB})_{6}$

(b)

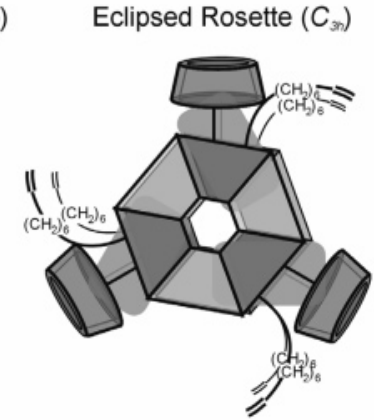

$1 b_{3} \cdot(D E B) \cdot 2 a$
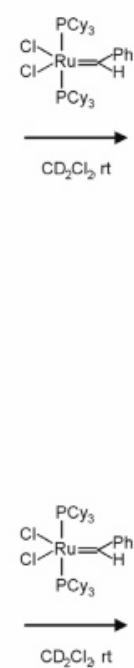
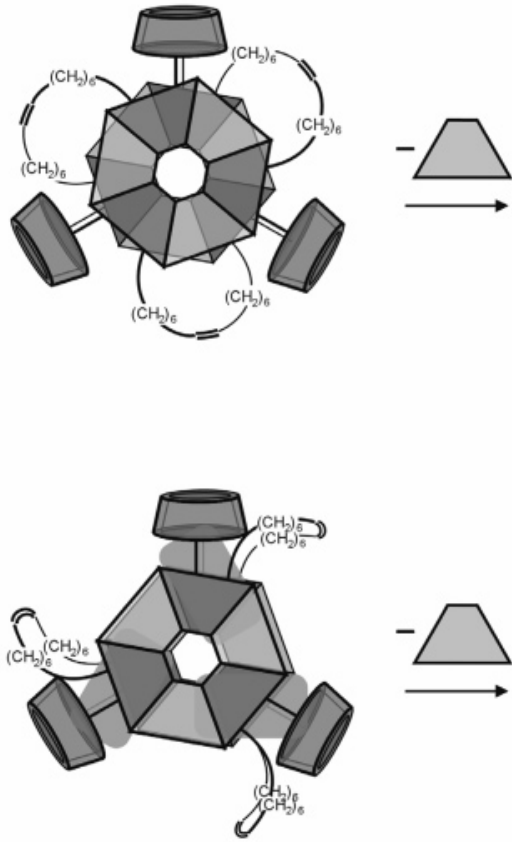

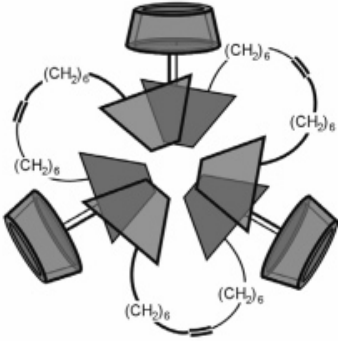

Cyclic Trimer

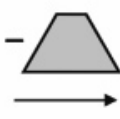

Cyclic Monomer

Figure 3. Ring closure metathesis reaction (RCM) of (a) assembly $\mathbf{1 b}_{3} \cdot(\mathrm{DEB})_{6}$ in the staggered conformation yielding a cyclic trimer, and (b) complex $\mathbf{1} \mathbf{b}_{3} \cdot(\mathrm{DEB})_{6} \cdot \mathbf{2}_{3}$ in the symmetrical eclipsed conformation yielding a cyclic monomer.

rosette layers reasonably implies that upon encapsulation of $\mathbf{2} \mathbf{a}_{3}$ a conformational change of the calix[4] arene dimelamine from staggered to symmetrical eclipsed has occurred also in solution (Figure 2).

Additional proof for the conformational change of assembly $\mathbf{1 a}_{3} \cdot(\mathrm{DEB})_{6}$ from staggered $\left(D_{3}\right)$ to symmetrical eclipsed $\left(C_{3 h}\right)$ after complexation in solution can be obtained from a ring closure metathesis (RCM) reaction (Figure 3 ). As described previously by our group, ${ }^{34,35}$ assembly $\mathbf{1 b}_{3} \cdot(\mathrm{DEB})_{6}$, with oct7-enyl side chain substituents on the melamine ring (Chart 1), forms a cyclic trimer (covalent linkage of the three calix[4]arene units) in the presence of the Grubbs catalyst ${ }^{36}$ in $\mathrm{CD}_{2} \mathrm{Cl}_{2}$. ${ }^{1} \mathrm{H}$ NMR and molecular modeling studies showed that assembly $\mathbf{1 b}_{3} \cdot(\mathrm{DEB})_{6}$ is exclusively present in staggered conformation ( $D_{3}$ isomer). After the RCM reaction, the exclusive formation of the cyclic trimer (Figure 3) was proven by MALDI-TOF MS and ${ }^{1} \mathrm{H}$ NMR spectroscopy.

In the staggered $D_{3}$ conformation, the two alkene chains connected to the same calix[4]arene are too far apart for an intracalix[4]arene reaction. This results in a geometry of the complex where the alkene chains connected to the melamines at different calix[4]arenes are close enough for an inter-calix[4]arene reaction, yielding the cyclic trimer instead of the cyclic monomer. However, in the eclipsed conformation, the two melamines on the same calix[4]arene would be close enough for an intracalix[4]arene reaction, yielding the cyclic monomer (Figure 3).

The complexation of $\mathbf{1 b}_{3} \cdot(\mathrm{DEB})_{6}$, containing oct-7-enyl side chain substituents, with $\mathbf{2 a}$ and the subsequent RCM reaction was studied by ${ }^{1} \mathrm{H}$ NMR spectroscopy and MALDI-TOF mass

(34) Cardullo, F.; Crego-Calama, M.; Snellink-Ruël, B. H. M.; Weidmann, J.L.; Bielejewska, A.; Fokkens, R. Nibbering, N. M. M.; Timmerman, P.; Reinhoudt, D. N. Chem. Commun. 2000, 367-368.

(35) Prins, L. J.; Jollife, K. A.; Hulst, R.; Timmerman, P.; Reinhoudt, D. N. $J$. Am. Chem. Soc. 2000, 122, 3617-3627.

(36) Grubbs, R. H.; Chang, S. Tetrahedron 1998, 54, 4413-4450. spectrometry, showing the same complexation behavior as that for $\mathbf{1} \mathbf{a}_{3} \cdot(\mathrm{DEB})_{6}$. Upon complexation of $\mathbf{2 a}$, the two initial signals for the $\mathrm{NH}_{\mathrm{DEB}}$ protons at 14.05 and $13.25 \mathrm{ppm}$ in the ${ }^{1} \mathrm{H} \mathrm{NMR}$ of $\mathbf{1 b}_{3} \cdot(\mathrm{DEB})_{6}$ have disappeared, while two new upfield shifted signals at 13.48 and 12.99 ppm have emerged (see Figure S-1). The presence of only two signals for the $\mathrm{NH}_{\text {DEB }}$ protons suggests that the conformation of the calix[4] arene dimelamines changes from staggered to (symmetrical) eclipsed upon complexation of $2 \mathbf{a}_{3}$. The ${ }^{1} \mathrm{H}$ NMR spectrum of the sample after the RCM reaction with $\mathbf{1}_{3} \cdot(\mathrm{DEB})_{6} \cdot \mathbf{2 a}_{3}$ shows that the signals for the two terminal vinylic protons at 5.8 and 4.9 ppm have disappeared, while a new signal for internal vinylic protons at $5.6 \mathrm{ppm}$ is present. MALDI-TOF mass spectrometry showed the mass signal $\left(m / z=1034.3\right.$; calcd for $\left.\mathrm{C}_{60} \mathrm{H}_{20} \mathrm{~N}_{12} \mathrm{O}_{14} \cdot \mathrm{H}^{+}=1033.6\right)$ corresponding to the cyclic monomer. Negligible signals for the cyclic dimer $(\sim 5 \%)$ and the cyclic trimer $(<1 \%)$ were observed, derived probably from some traces of assembly $\mathbf{1 b}_{3}$. $(\mathrm{DEB})_{6}$ without $\mathbf{2 a}$. Since the formation of the monomer is only possible if the calix[4] arene dimelamines in $\mathbf{1}_{3} \cdot(\mathrm{DEB})_{6} \cdot \mathbf{2} \mathbf{a}_{3}$ have a (symmetrical) eclipsed conformation, the RCM reaction with $\mathbf{1} \mathbf{b}_{3} \cdot(\mathrm{DEB})_{6} \cdot \mathbf{2} \mathbf{a}_{3}$ gives indirect proof of the conformational change in assembly $\mathbf{1 a}_{3} \cdot(\mathrm{DEB})_{6}$ from staggered $\left(D_{3}\right)$ to symmetrical eclipsed $\left(C_{3 h}\right)$ upon encapsulation of $\mathbf{2} \mathbf{a}_{3}$ in solution.

Before encapsulation of the $\mathbf{2} \mathbf{a}_{3}$ trimer, the two melamines of one calix[4]arene are in an antiparallel (staggered) orientation to allow interactions between the $\pi$-surface of the melamines, ${ }^{37}$ but these interactions are lost after the encapsulation of $\mathbf{2 a}$. The change from a staggered conformation to a symmetrical eclipsed conformation of the rosette can then be explained by the Hunter-Sanders model for $\pi-\pi$ stacking. ${ }^{38}$ The $\sigma$-framework

(37) Meyer, E. A.; Castellano, R. K.; Diederich, F. Angew. Chem., Int. Ed. 2003 , $42,1210-1250$

(38) Hunter, C. A.; Sanders, J. K. M. J. Am. Chem. Soc. 1990, 112, 55255534. 


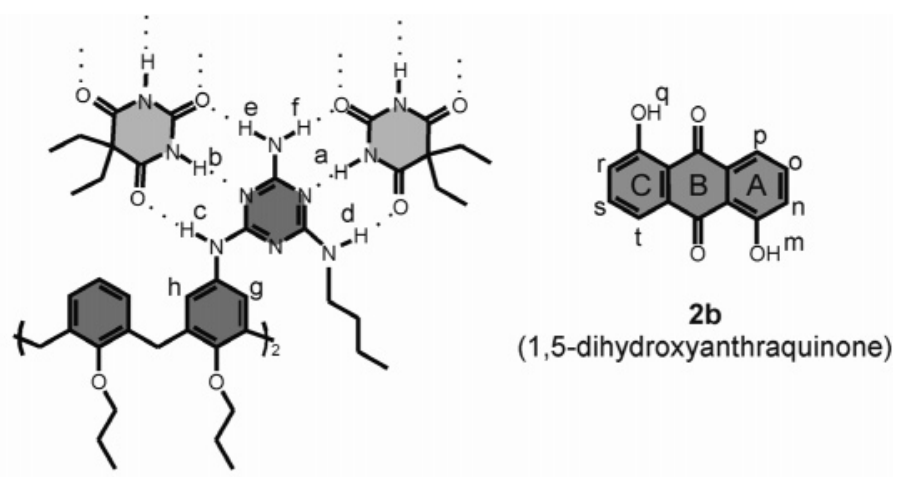

(a)

(b)

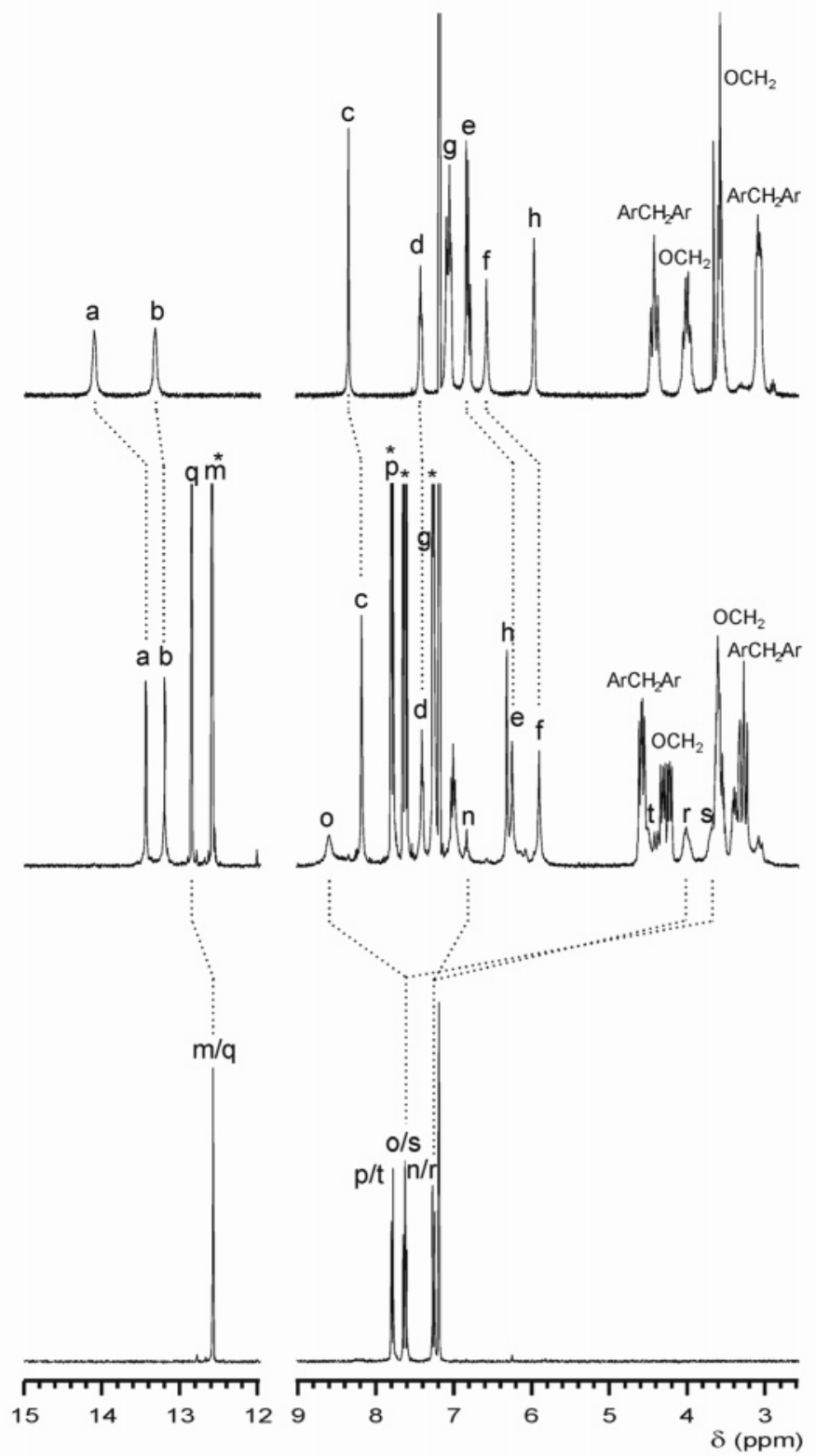

Figure 4. Part of the ${ }^{1} \mathrm{H}$ NMR spectrum $\left(400 \mathrm{MHz}, \mathrm{CDCl}_{3}\right)$ of (a) receptor $\mathbf{1 a}_{3} \cdot(\mathrm{DEB})_{6}$, (b) complex $\mathbf{1 a}_{3} \cdot(\mathrm{DEB})_{6} \cdot \mathbf{2} \mathbf{b}_{3}$, and (c) guest molecule $\mathbf{2} \mathbf{b}$. The signals corresponding to free $\mathbf{2} \mathbf{b}$ are marked with $*$.

and the $\pi$-electrons are considered separately. The model shows that the $\pi-\sigma$ attractions overcome the $\pi-\pi$ repulsions, giving the net favorable $\pi-\pi$ interactions. This model reveals that for two electron-deficient rings, such as, for example, the melamine ring of the receptor and the center ring (ring B, see Figure 1) of $2 \mathbf{a}$, the $\pi-\pi$ repulsion is minimized, and therefore, stacking of these rings is more favorable. Furthermore, in an offset $\pi$-stacked geometry, as can be seen between the melamine units of the receptor and the B-ring of $\mathbf{2} \mathbf{a}$, the $\pi-\sigma$ attraction will dominate and favor the stacking.

Selectivity Studies with Receptor $1 \mathbf{a}_{3} \cdot(\mathrm{DEB})_{6}$. To study the encapsulation selectivity of the self-assembled host $\mathbf{1 a}_{3} \cdot(\mathrm{DEB})_{6}$, 
a series of anthraquinone derivatives with one (2e, $\mathbf{2 f})$ or more $(\mathbf{2 a}-\mathbf{d}, \mathbf{2 g})$ hydroxyl groups at different positions $\left(\mathrm{Y}^{1-8}\right.$; see Chart 1) of the anthraquinone skeleton and anthracene (4) were chosen as guest molecules.

Complexation of 1,5-dihydroxyanthraquinone (2b) by receptor $\mathbf{1 a}_{3} \cdot(\mathrm{DEB})_{6}$ is observed in solution by ${ }^{1} \mathrm{H}$ NMR spectroscopy. The ${ }^{1} \mathrm{H}$ NMR spectrum showed that upon addition of 10 equiv of $\mathbf{2 b}$ to a solution of $\mathbf{1 a}_{3} \cdot(\mathrm{DEB})_{6}\left(1.0 \mathrm{mM}\right.$ in $\left.\mathrm{CDCl}_{3}\right)$ a different set of signals for the hydrogen-bonded $\mathrm{H}_{\mathrm{a}-\mathrm{e}}$ of the receptor emerged, confirming the formation of the complex $\mathbf{1 a}_{3}{ }^{\circ}(\mathrm{DEB})_{6} \cdot$ $\mathbf{2 b}_{3}$ (Figure 4). (The assignment of the protons always refers to a pattern in which the protons are positioned similarly as for $\mathbf{2 a}$; see Figure 1.) Only chemical shifts for the complex $\mathbf{1} \mathbf{a}_{3}$. $(\mathrm{DEB})_{6} \cdot \mathbf{2 b}_{3}$ and free $\mathbf{2 b}$ were observed. ${ }^{39}$ Large upfield shifts for the guest molecules $\mathbf{2} \mathbf{b}$ are observed, indicating their encapsulation. The aromatic protons $\mathrm{H}_{\mathrm{r}}, \mathrm{H}_{\mathrm{s}}$, and $\mathrm{H}_{\mathrm{t}}$ (Figure 4 ) of $\mathbf{2 b}$ have shifted $\sim 3$ ppm upfield, demonstrating that ring $\mathrm{C}$ is partially included in the calix[4]arene cone. The intramolecularly hydrogen-bonded protons $\mathrm{H}_{\mathrm{q}}$ are shifted $0.26 \mathrm{ppm}$ downfield compared to the position of these protons in the free guest. The peaks of the hydrogen-bonded $\mathrm{NH}_{\mathrm{DEB}}$ protons $\mathrm{H}_{\mathrm{a}}$ and $\mathrm{H}_{\mathrm{b}}$ in the complex $1 \mathbf{a}_{3} \cdot(\mathrm{DEB})_{6} \cdot \mathbf{2} \mathbf{b}_{3}$ are shifted upfield 0.66 and $0.11 \mathrm{ppm}$, respectively. ${ }^{31}$ Protons $\mathrm{H}_{\mathrm{e}}$ and $\mathrm{H}_{\mathrm{f}}$ situated in the internal part of the rosette cavity show a large upfield shift of 0.56 and 0.68 ppm, respectively, with respect to the free assembly $\mathbf{1 a}_{3} \cdot(\mathrm{DEB})_{6}$. Integrals of the corresponding signals in the ${ }^{1} \mathrm{H}$ NMR spectrum show that three $\mathbf{2} \mathbf{b}$ guest molecules are encapsulated by the $\mathbf{1 a}_{3}$. (DEB) 6 (1:3 stoichiometry). In summary, the ${ }^{1} \mathrm{H}$ NMR studies confirm the encapsulation of $\mathbf{2} \mathbf{b}_{3}$ between the two rosette planes.

Complexation of $\mathbf{2} \mathbf{b}$ was also observed in the solid state by $\mathrm{X}$-ray crystal structure analysis (Figure 5). Cubic red crystals $(0.3-1 \mathrm{mM})$ were obtained from diffusion of hexane into a solution of 1,5-dihydroxyanthraquinone (2b) and $\mathbf{1 a}_{3} \cdot(\mathrm{DEB})_{6}$ in $\mathrm{CH}_{2} \mathrm{Cl}_{2}$. The structure of complex $\mathbf{1} \mathbf{a}_{3} \cdot(\mathrm{DEB})_{6} \cdot \mathbf{2} \mathbf{b}_{3}$ is similar to the structure of complex $\mathbf{1} \mathbf{a}_{3} \cdot(\mathrm{DEB})_{6} \cdot \mathbf{2} \mathbf{a}_{3}{ }^{26}$ The two melamines of each calix[4]arene 1a are in eclipsed orientation with respect to each other, and the electron-deficient aromatic B-ring of the 1,5-dihydroxyanthraquinone $\mathbf{2 b}$ is complexed between the two relatively electron-poor aromatic rings of these melamine units. As for the encapsulation of $\mathbf{2 a}$, the hydroxyl functionalities of $\mathbf{2 b}$ at the $\mathrm{Y}^{1}$-position are pointing outward of the center of the rosette floors, avoiding steric interactions with the calix[4]arene cone. Because $\mathbf{2 b}$ lacks an $\mathrm{OH}$ group in the $\mathrm{Y}^{2}$-position, $\mathbf{2} \mathbf{b}$ is not able to form an intermolecular hydrogen bond between this group and the carbonyl group of the adjacent guest molecule, different from what happens with $\mathbf{2 a}$. The absence of intermolecular hydrogen bonds has no significant effect on the position of the guest with respect to the receptor.

The intermolecular separation between the two rosette layers increases upon encapsulation from $3.5 \AA$ at the edges and 3.2 $\AA$ in the center for $1 \mathbf{a}_{3} \cdot(\mathrm{DEB})_{6}{ }^{28}$ to $6.7 \AA$ at the edges and 6.8 $\AA$ in the center for $1 \mathbf{a}_{3} \cdot(\mathrm{DEB})_{6} \cdot \mathbf{2} \mathbf{b}_{3}$. The crystal structures of $\mathbf{1} \mathbf{a}_{3} \cdot(\mathrm{DEB})_{6} \cdot \mathbf{2} \mathbf{a}_{3}{ }^{26}$ and $\mathbf{1} \mathbf{a}_{3} \cdot(\mathrm{DEB})_{6} \cdot \mathbf{2} \mathbf{b}_{3}$ are completely isomorphic. The only difference is the location of the $\mathrm{OH}$ groups on the guest molecule.

After the encapsulation of $\mathbf{2} \mathbf{b}$ by the receptor $\mathbf{1 a}_{3} \cdot(\mathrm{DEB})_{6}$, the influence in the complexation of the $\mathrm{OH}$ substituents at different positions of the anthraquinone skeleton was studied.

(39) All the signals in the ${ }^{1} \mathrm{H}$ NMR spectrum of complex $\mathbf{1 a}_{3} \cdot(\mathrm{DEB})_{6} \cdot \mathbf{2 b}_{3}$ were assigned using $2 \mathrm{D}{ }^{1} \mathrm{H}$ NMR experiments. (a)

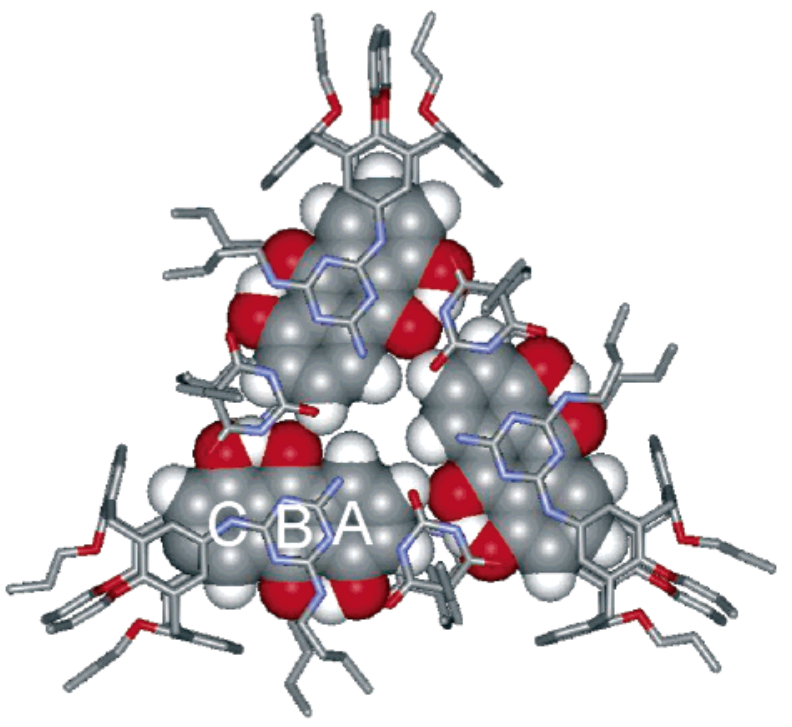

(b)

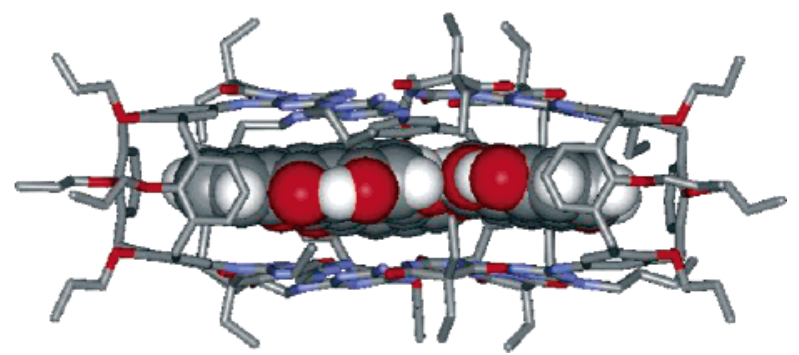

Figure 5. (a) Top and (b) side view of the crystal structure of the complex $1 \mathbf{a}_{3} \cdot(\mathrm{DEB})_{6} \cdot \mathbf{2}_{3}$. A stick model is used for the molecular box $\mathbf{1 a}_{3} \cdot(\mathrm{DEB})_{6}$, while a space-filling representation is chosen for the guest molecules $\mathbf{2} \mathbf{b}$. Hydrogen atoms of the assembly are not shown for clarity.

Although the hydroxyl groups in $\mathbf{2} \mathbf{b}$ did not hinder the complexation, it was reasoned that a different substitution pattern in the ring $\mathrm{C}$ of the anthraquinone skeleton might decrease the complexation ability of the host due to steric interactions between this ring and the calix[4]arene.

Addition of 1,8-dihydroxyanthraquinone (2c) (10 equiv) to assembly $\mathbf{1 a}_{3} \cdot(\mathrm{DEB})_{6}\left(1.0 \mathrm{mM}\right.$ in $\left.\mathrm{CDCl}_{3}\right)$ led also to large shifts of the ${ }^{1} \mathrm{H}$ NMR signals for the guest molecule $\mathbf{2 c}$, indicating the encapsulation of $\mathbf{2} \mathbf{c}_{3}$ (spectrum not shown). The intramolecular hydrogen-bonded $\mathrm{OH}_{\mathrm{m}}\left(\mathrm{Y}^{1}\right.$-position) and $\mathrm{OH}_{\mathrm{t}}\left(\mathrm{Y}^{8}\right.$ position) of the guest $2 \mathrm{c}$ shifted $0.40 \mathrm{ppm}$ upfield and $0.25 \mathrm{ppm}$ downfield, respectively, upon complexation. Furthermore, the hydrogen-bonded $\mathrm{NH}_{\text {DEB }}$ protons $\mathrm{H}_{\mathrm{a}}$ and $\mathrm{H}_{\mathrm{b}}$ in the complex $\mathbf{1} \mathbf{a}_{3}$. $(\mathrm{DEB})_{6} \cdot \mathbf{2} \mathbf{c}_{3}$ are shifted $0.76 \mathrm{ppm}$ upfield and $0.04 \mathrm{ppm}$ downfield, respectively.

The orientation of molecule $\mathbf{2} \mathbf{c}$ in the complex $\mathbf{1 a}_{3} \cdot(\mathrm{DEB})_{6} \cdot$ $\mathbf{2 c}_{3}$ is extrapolated from the X-ray structures of complexes $\mathbf{1} \mathbf{a}_{3}$. $(\mathrm{DEB})_{6} \cdot \mathbf{2}_{3}$ and $\mathbf{1} \mathbf{a}_{3} \cdot(\mathrm{DEB})_{6} \cdot \mathbf{2}_{3}$. Figure 6 shows that both area $i$ and $i i$ in the receptor cavity of these two crystal structures are inaccessible for guest molecules with functionalities at the $\mathrm{Y}^{6}$ and $\mathrm{Y}^{8}$-positions in the anthraquinone skeleton (this refers to the orientation of the guest molecules where ring $\mathrm{C}$ is included in the calix[4]arene cone). On this basis, it is assumed that $\mathbf{2 c}$ is complexed with the 1-hydroxyl group ( $\mathrm{Y}^{1}=\mathrm{OH}$; ring $\mathrm{A}$ ) pointing inward relative to the rosette plane (Figure $7 \mathrm{a}$ ). In this way, the 8-hydroxyl group of $2 \mathrm{c}\left(\mathrm{Y}^{8}=\mathrm{OH}\right.$; ring $\mathrm{C}$ ) occupies 

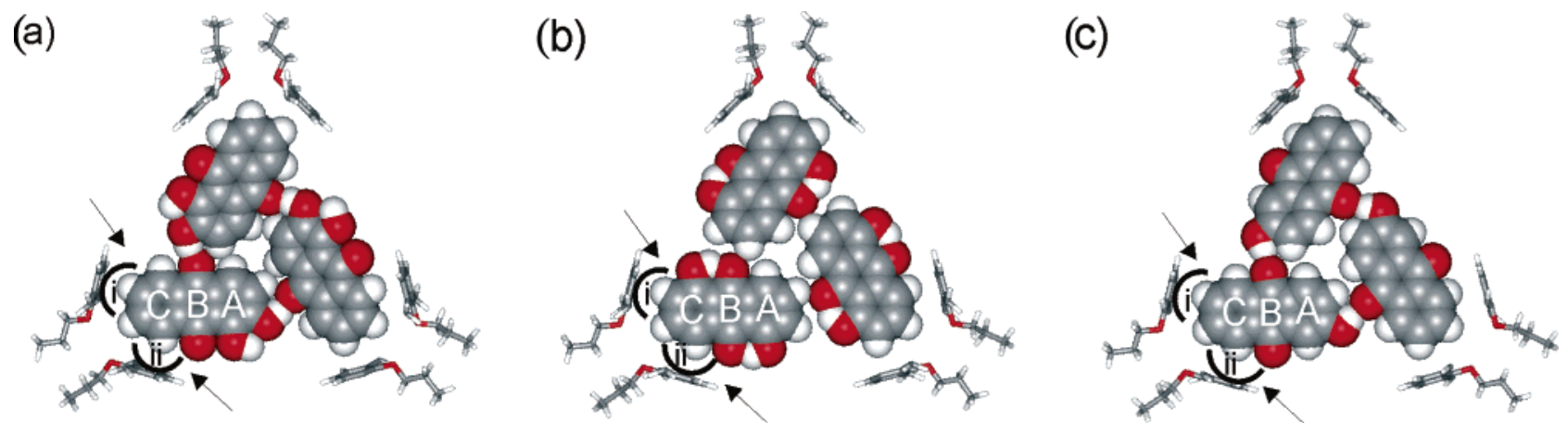

Figure 6. Part of the X-ray crystal structures of the complex (a) $\mathbf{1 a}_{3} \cdot(\mathrm{DEB})_{6} \cdot \mathbf{2} \mathbf{a}_{3}$, (b) $\mathbf{1} \mathbf{a}_{3} \cdot(\mathrm{DEB})_{6} \cdot \mathbf{2} \mathbf{b}_{3}$, and (c) $\mathbf{1 a}_{3} \cdot(\mathrm{DEB})_{6} \cdot \mathbf{2} \mathbf{f}_{3}$ (for a direct comparison of the complete X-ray crystal structures, see Supporting Information); $i$ and $i i$ (see arrows) denote the inaccessible areas, due to steric strain, for functionalities present at the anthraquinone skeleton ( $\mathrm{Y}^{6}$ - or $\mathrm{Y}^{8}$-positions; see Chart 1 for assignment of the positions). A stick model is used to visualize a part of the calix[4]arene units of 1a, while a space-filling representation is chosen for the guest molecules $\mathbf{2 a}$, $\mathbf{2} \mathbf{b}$, and $\mathbf{2} \mathbf{f}$.

a)

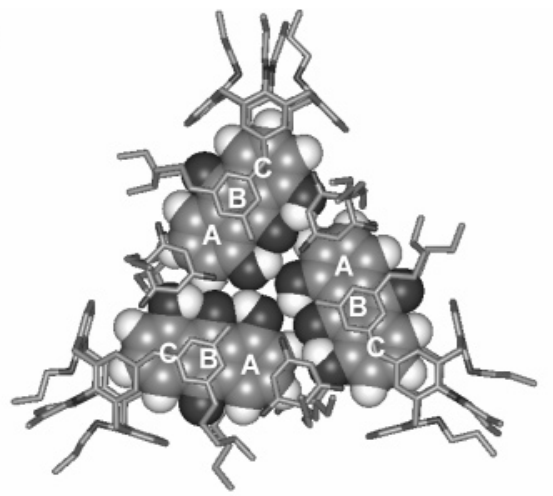

c)

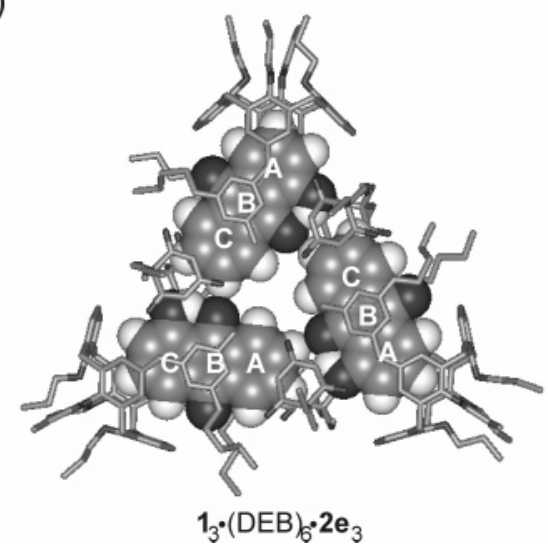

b)

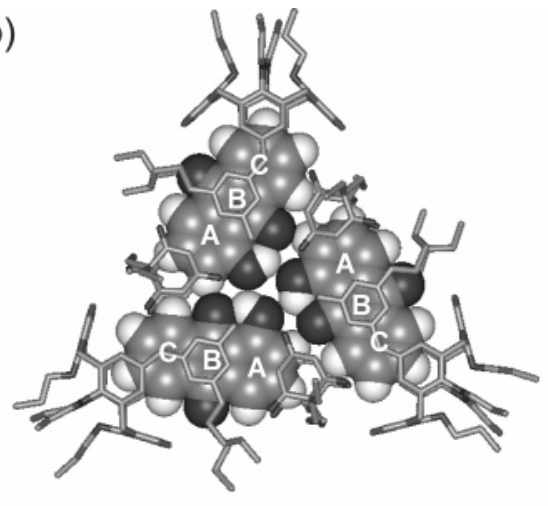

$1_{3} \cdot(\mathrm{DEB}) \cdot 2 \mathrm{e}_{3}$

d)

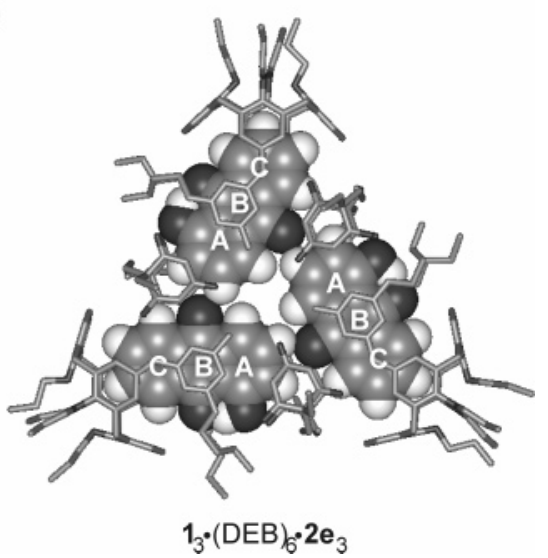

Figure 7. Gas-phase-minimized structures of (a) $\mathbf{1 a}_{3} \cdot(\mathrm{DEB})_{6} \cdot \mathbf{2} \mathbf{c}_{3}$ and $(\mathrm{b}-\mathrm{d})$ the different possible isomers of $\mathbf{1 a}_{3} \cdot(\mathrm{DEB})_{6} \cdot \mathbf{2} \mathbf{e}_{3}$. In (b), the hydroxyl groups 1-OH $\left(\mathrm{Y}^{1}=\mathrm{OH}\right.$; ring $\left.\mathrm{A}\right)$ are pointing inward of the rosette plane close to the center of the plane, while in (c), these hydroxyl groups are pointing inward of the rosette plane close to the edge of the plane. In (d), the hydroxyl groups are pointing outward of the rosette plane. The experimentally observed structure corresponds to the structure in Figure $7 \mathrm{~d}$. Stick models are used for the molecular cage $\mathbf{1 a}_{3} \cdot(\mathrm{DEB})_{6}$, while space-filling representations are chosen for the guest molecules. Hydrogen atoms of $\mathbf{1}_{3} \cdot(\mathrm{DEB})_{6}$ are omitted for clarity.

the same space in the receptor cavity as the 5-hydroxyl group (ring $\mathrm{C}$ ) of guest $\mathbf{2} \mathbf{b}$ in complex $\mathbf{1}_{3} \cdot(\mathrm{DEB})_{6} \cdot \mathbf{2}_{3}$. Thus, the C-ring suffers no steric hindrance with the calix[4]arene cone.

From the X-ray structures of $\mathbf{1 a}_{3} \cdot(\mathrm{DEB})_{6} \cdot \mathbf{2 a}_{3}$ and $\mathbf{1 a}_{3} \cdot(\mathrm{DEB})_{6} \cdot$ $\mathbf{2} \mathbf{b}_{3}$, it can also be extrapolated that receptor $1 \mathbf{a}_{3} \cdot(\mathrm{DEB})_{6}$ should not complex $\mathbf{2} \mathbf{d}$ because in all possible orientations of this guest a hydroxyl group will occupy either area $i$ or $i i$ (Figure 6). As predicted, after addition of 1,2,5,8-hydroxyanthraquinone (2d) to $\mathbf{1 a}_{3} \cdot(\mathrm{DEB})_{6}$, no changes in the chemical shifts of either guest or host were observed, indicating that no complexation has occurred.
Subsequently, and to examine the importance of the number and the position of hydroxyl functionalities at ring A, guest molecules $\mathbf{2 e}-\mathbf{g}$ were added to assembly $\mathbf{1 a}_{3} \cdot(\mathrm{DEB})_{6}$. The addition of 1-hydroxyanthraquinone (2e, 10 equiv), containing only one $\mathrm{OH}$ at the $\mathrm{Y}^{1}$-position, to the assembly $\mathbf{1 a}_{3} \cdot(\mathrm{DEB})_{6}$ (1.0 $\mathrm{mM}$ in $\mathrm{CDCl}_{3}$ ) gave upfield shifts of $3.50 \mathrm{ppm}$ for $\mathrm{H}_{\mathrm{t}}$ of guest $2 \mathrm{e}$ and upfield shifts of 0.22 and $0.14 \mathrm{ppm}$ for $\mathrm{H}_{\mathrm{a}}$ and $\mathrm{H}_{\mathrm{b}}$ of the receptor in the ${ }^{1} \mathrm{H}$ NMR studies, respectively, indicating that complex $1 \mathbf{a}_{3} \cdot(\mathrm{DEB})_{6} \cdot \mathbf{2 e}_{3}$ is formed (see Figures 1 and 5 for similar assignments). Under these conditions, only a small amount of the complex is present, indicating a lower binding 
constant for $\mathbf{2} \mathbf{e}$ compared to that of guests $\mathbf{2} \mathbf{a}-\mathbf{c}$. The guest molecule $\mathbf{2 e}$ can be encapsulated with the hydroxyl functionality pointing either inward (Figure 7b,c) or outward (Figure 7d) relative to the center of the complex plane. As observed for guest $\mathbf{2 b}$, no shift of the $\mathrm{OH}_{\mathrm{m}}\left(\mathrm{Y}^{1}\right.$-position, ring $\left.\mathrm{A}\right)$ signal $(\delta=$ $12.55 \mathrm{ppm}$ ) was observed in the ${ }^{1} \mathrm{H}$ NMR spectrum of the complex formed with $\mathbf{2 e}$, indicating the same outward orientation for this proton (Figure 7d).

Large shifts of the aromatic protons $\mathrm{H}_{\mathrm{r}}, \mathrm{H}_{\mathrm{s}}$, and $\mathrm{H}_{\mathrm{t}}(\Delta \delta=$ $3.12-3.83 \mathrm{ppm}$ ) were observed when 2-hydroxyanthraquinone (2f, 4 equiv), containing only one hydroxyl group ( $\mathrm{Y}^{2}$-position), and purpurin (2g, 4 equiv), with three hydroxyl groups in ring A $\left(\mathrm{Y}^{1,2}, \mathrm{Y}^{4}\right.$-position; Chart 1$)$, were added to $\mathbf{1 a}_{3} \cdot(\mathrm{DEB})_{6}(1.0$ $\mathrm{mM}$ in $\mathrm{CDCl}_{3}$ ). Also, in these ${ }^{1} \mathrm{H}$ NMR spectra, a different set of signals for the $\mathrm{H}_{\mathrm{a}}$ and $\mathrm{H}_{\mathrm{b}}$ protons of $\mathbf{1 a}_{3} \cdot(\mathrm{DEB})_{6} \cdot \mathbf{2 f}_{3}$ and $\mathbf{1} \mathbf{a}_{3} \cdot$ $(\mathrm{DEB})_{6} \cdot \mathbf{2} \mathbf{g}_{3}$ were observed. Furthermore, the large downfield shift of the 2-hydroxyl group $\left(\mathrm{OH}_{n}\right)$ of $\mathbf{2} \mathbf{f}$ and $\mathbf{2} \mathbf{g}$ indicates that in both $\mathbf{1 a}_{3} \cdot(\mathrm{DEB})_{6} \cdot \mathbf{2 f}_{3}$ and $\mathbf{1} \mathbf{a}_{3} \cdot(\mathrm{DEB})_{6} \cdot \mathbf{2 g}_{3}$ an intermolecular hydrogen-bonded network is formed between the encapsulated guest molecules, as it was observed for complex $1 \mathbf{a}_{3} \cdot(\mathrm{DEB})_{6}{ }^{\circ}$ $\mathbf{2 a}_{3}$. For $\mathbf{1 a}_{3} \cdot(\mathrm{DEB})_{6} \cdot \mathbf{2} \mathbf{f}_{3}$, this has also been verified by an X-ray crystal structure (Figure 6c). This structure is also completely isomorphic with the other two host-guest crystal structures (Figure 6). Therefore, the mode of complexation of guests $\mathbf{2 f}$ and $\mathbf{2} \mathbf{g}$ by $\mathbf{1 a}_{3} \cdot(\mathrm{DEB})_{6}$ is the same as that for $\mathbf{2} \mathbf{a}$, indicating that the complexation is not substantially affected even when three hydroxyl groups are present at ring A.

The complexation of anthracene (4) and anthraquinone (2h) was also examined. Addition of anthracene (4, 10 equiv), lacking both carbonyl and hydroxyl functionalities, to $\mathbf{1 a}_{3} \cdot(\mathrm{DEB})_{6}(1.0$ $\mathrm{mM}$ in $\mathrm{CDCl}_{3}$ ) causes no shift of the ${ }^{1} \mathrm{H}$ NMR signals. The central aromatic ring of $\mathbf{4}$ is more electron rich compared to that of $\mathbf{2} \mathbf{a}$; therefore, the $\pi-\pi$ repulsion possibly dominates over the $\pi-\sigma$ attraction and thus prevents $\pi-\pi$ stacking of the guest between the two melamine units. Even anthraquinone (2h, 10 equiv), lacking only the hydroxyl groups, did not show shifts of the signals in the ${ }^{1} \mathrm{H}$ NMR spectrum, evidencing the importance of at least one hydroxyl group for the complexation.

In summary, complexation of anthraquinone derivatives $\mathbf{2 a}-\mathbf{h}$ only occurs when there are no hydroxyl groups at the $\mathrm{Y}^{6}$ - and $\mathrm{Y}^{8}$-positions in the anthraquinone skeleton (referring to the orientation of the guest molecules in the complex where ring $\mathrm{C}$ is included in the calix[4]arene cone); otherwise, the steric strain between the substituents and the receptor prevents the complexation. When a hydroxyl group is at the $\mathrm{Y}^{2}$-position (ring A), a strong intermolecular hydrogen-bonded network is formed among the three encapsulated guests. ${ }^{40}$ Furthermore, hydroxyl groups at ring A do not substantially affect the complexation. The carbonyl groups in ring B and at least one hydroxyl group in the anthraquinone skeleton are required for complexation.

Calculation of the Binding Constant of Guest Molecules and $1 \mathbf{1 a}_{3} \cdot(\mathrm{DEB})_{6} \mathbf{}^{{ }^{1}} \mathbf{H}$ NMR Titration. The binding constant for the complexation of $\mathbf{2 a}$ with $\mathbf{1 a}_{3} \cdot(\mathrm{DEB})_{6}$ was determined by

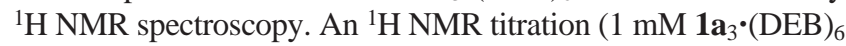
in $\mathrm{CDCl}_{3}$ ) was performed by monitoring the percentages of $\mathbf{1 a}_{3}$. $(\mathrm{DEB})_{6}$ and $\mathbf{1} \mathbf{a}_{3} \cdot(\mathrm{DEB})_{6} \cdot \mathbf{2}_{3}$ present in solution. A binding constant, $K_{\mathrm{a}}$, was estimated from the ${ }^{1} \mathrm{H}$ NMR titration data by using the eqs $1-4$ (see below). Only two species, $\mathbf{1 a}_{3} \cdot(\mathrm{DEB})_{6}$ and $\mathbf{1} \mathbf{a}_{3} \cdot(\mathrm{DEB})_{6} \cdot \mathbf{2} \mathbf{a}_{3}$, were observed by ${ }^{1} \mathrm{H}$ NMR spectroscopy; therefore, it was assumed that complex $\mathbf{1 a}_{3} \cdot(\mathrm{DEB})_{6} \cdot \mathbf{2} \mathbf{a}_{3}$ is formed in one step.

$$
\begin{gathered}
\mathbf{1 a}_{3} \cdot(\mathrm{DEB})_{6}+3 \mathbf{2} \mathbf{a} \rightleftarrows \mathbf{1} \mathbf{a}_{3} \cdot(\mathrm{DEB})_{6} \cdot \mathbf{2} \mathbf{a}_{3} \\
K_{\mathrm{a}}=\frac{\left[\mathbf{1} \mathbf{a}_{3} \cdot(\mathrm{DEB})_{6} \cdot \mathbf{2} \mathbf{a}_{3}\right]}{[\mathbf{2} \mathbf{a}]^{3}\left[\mathbf{1} \mathbf{a}_{3} \cdot(\mathrm{DEB})_{6}\right]} \\
{\left[\mathbf{1 a}_{3} \cdot(\mathrm{DEB})_{6}\right]_{\mathrm{tot}}=\left[\mathbf{1 a}_{3} \cdot(\mathrm{DEB})_{6}\right]+\left[\mathbf{1} \mathbf{a}_{3} \cdot(\mathrm{DEB})_{6} \cdot \mathbf{2} \mathbf{a}_{3}\right]} \\
{[\mathbf{2} \mathbf{a}]_{\mathrm{tot}}=[\mathbf{2} \mathbf{a}]+3\left[\mathbf{1 a}_{3} \cdot(\mathrm{DEB})_{6} \cdot \mathbf{2 a}_{3}\right]}
\end{gathered}
$$

The amount of free guest $\mathbf{2 a}$ is difficult to measure precisely because it is hardly present in the solution; therefore, the $K_{\mathrm{a}}$ value cannot be calculated accurately. The concentration of free guest is recalculated indirectly from the concentration of the complex that is formed $\left(\left[\mathbf{1 a}_{3} \cdot(\mathrm{DEB})_{6} \cdot \mathbf{2} \mathbf{a}_{3}\right]\right.$, eq 4). A $K_{\mathrm{a}} \geq 10^{10}$ $\mathrm{M}^{-3}$ was estimated. For a more precise calculation of the binding constant, $K_{\mathrm{a}}$, a different experiment was carried out with lower $\left[\mathbf{1 a}_{3} \cdot(\mathrm{DEB})_{6}\right]_{\text {tot }}$ and $[\mathbf{2 a}]_{\text {tot }}$. The ${ }^{1} \mathrm{H}$ NMR spectrum of assembly $\mathbf{1 a}_{3} \cdot(\mathrm{DEB})_{6}\left(0.1 \mathrm{mM}\right.$ in $\left.\mathrm{CDCl}_{3}\right)$ with 2 equiv of $\mathbf{2 a}$ clearly showed the presence of free $\mathbf{2 a}{ }^{41}$ With the calculated $\left[\mathbf{1 a}_{3}\right.$. $\left.(\mathrm{DEB})_{6}\right]_{\text {tot }}(0.043 \mathrm{mM})$ by integration of the $\mathrm{NH}_{\mathrm{DEB}}$ protons and the $\mathrm{ArCH}_{2} \mathrm{Ar}$ bridge protons and a total guest concentration of $0.20 \mathrm{mM}$, a $K_{\mathrm{a}}$ of $10^{11} \mathrm{M}^{-3}$ was estimated.

Isothermal Titration Calorimetry. Isothermal titration calorimetry (ITC) was used to quantify the thermodynamic parameters $\Delta G^{\circ}, \Delta H^{\circ}, T \Delta S^{\circ}$, and also the association constant $\left(K_{\mathrm{a}}\right)$ for the encapsulation of the guest molecules $\mathbf{2} \mathbf{a}-\mathbf{h}$ by receptor $\mathbf{1 a}_{3} \cdot(\mathrm{DEB})_{6}$. As an example, Figure 8 shows the results of the ITC measurement for the formation of $\mathbf{1 a}_{3} \cdot(\mathrm{DEB})_{6} \cdot \mathbf{2} \mathbf{a}_{3}$ using $3.0 \mathrm{mM}$ solutions of $\mathbf{2 a}$ in 1,2-dichloroethane (1,2-DCE) inside the ITC cell and $10 \mathrm{mM}$ of $\mathbf{1 a}_{3} \cdot(\mathrm{DEB})_{6}$ in $1,2-\mathrm{DCE}$ as titrant.

Cooperative binding of anthraquinone derivatives $\mathbf{2 a}$ by $\mathbf{1 a}_{3}$. $(\mathrm{DEB})_{6}$ is observed since it was not possible to fit the ITC data to an independent 1:3 binding model. Because only free assembly, free guest, and complex are observed in solution with ${ }^{1} \mathrm{H}$ NMR spectroscopy, complex $\mathbf{1} \mathbf{a}_{3} \cdot(\mathrm{DEB})_{6} \cdot \mathbf{2} \mathbf{a}_{3}$ is considered to be directly formed from assembly $\mathbf{1 a}_{3} \cdot(\mathrm{DEB})_{6}$ and three molecules of $\mathbf{2 a}$. Therefore, the association constant $\left(K_{\mathrm{a}}\right)$ can be written as described in eq 2 (see above; $K_{\mathrm{a}}$ is expressed in $\left.\mathrm{M}^{-3}\right)$.

In the beginning of the titration, the concentration of assembly is low, and therefore, a part of the assembly is dissociated. To correct for this, a more precise estimation of the mass balance was calculated based on the formation constant for $\mathbf{1 a}_{3} \cdot(\mathrm{DEB})_{6} \cdot{ }^{42}$ Equation 5 describes the formation of assembly $\mathbf{1 a}_{3} \cdot(\mathrm{DEB})_{6}\left(K_{\mathrm{f}}\right.$ is the formation constant of the assembly expressed in $\mathrm{M}^{-8}$ ). From eqs 2 (see above) and 5, the association constant for the encapsulation of $\mathbf{2} \mathbf{a}$ is calculated (eq 6). Heat effects caused by

(40) Other intermolecular hydrogen bonds are present in the X-ray crystal structures of the guest molecules between the $\mathrm{CH}$ and the carbonyl groups of adjacent guest molecules. However, it is unlikely that the strength of the complexation of guest molecules is affected by the formation of these hydrogen bonds because anthraquinone $(\mathbf{2 h})$, which could also form these hydrogen bonds, is not encapsulated.

(41) The amount of $\mathrm{H}_{2} \mathrm{O}$ that is present in $\mathrm{CDCl}_{3}$ at this concentration and the lower concentration of building blocks $1 \mathrm{a}$ and DEB shifted the equilibrium to the separate building blocks. Therefore, assembly $\mathbf{1 a}_{3} \cdot(\mathrm{DEB})_{6}$ at this concentration was not formed quantitatively.

(42) ten Cate, M. G. J.; Huskens, J.; Crego-Calama, M.; Reinhoudt, D. N. Chem.-Eur. J. 2004, 10, 3632-3639. 


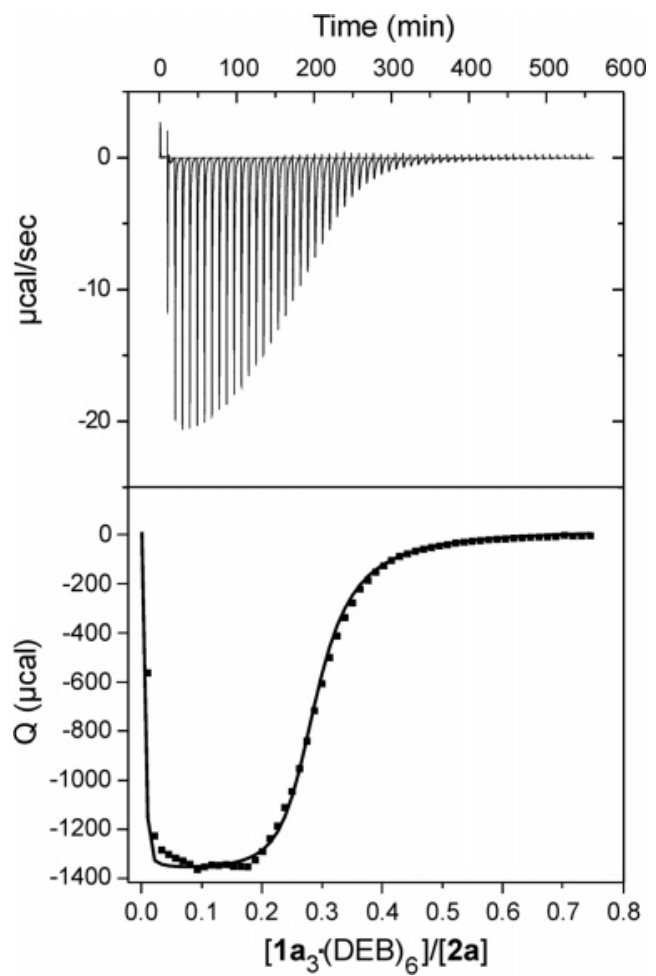

Figure 8. Top: ITC measurement for the formation of $\mathbf{1 a}_{3} \cdot(\mathrm{DEB})_{6} \cdot \mathbf{2}_{3}$; cell $=3.0 \mathrm{mM} 2 \mathbf{a}$, buret $=10.0 \mathrm{mM} \mathrm{1a}{ }_{3} \cdot(\mathrm{DEB})_{6}$. Bottom: Binding isotherm fitted to a $1: 3$ binding algorithm.

dissociation of the assembly were corrected from data obtained from dilution experiments.

$$
\begin{gathered}
K_{\mathrm{f}}=\frac{\left[\mathbf{1 a}_{3} \cdot(\mathrm{DEB})_{6}\right]}{[\mathbf{1} \mathbf{a}]^{3}[\mathrm{DEB}]^{6}} \\
K_{\mathrm{a}}=\frac{\left[\mathbf{1 a}_{3} \cdot(\mathrm{DEB})_{6} \cdot \mathbf{2} \mathbf{a}_{3}\right]}{K_{\mathrm{f}} \times[\mathbf{1 a}]^{3}[\mathrm{DEB}]^{6}[\mathbf{2 a}]^{3}}
\end{gathered}
$$

Curve fitting of the binding isotherms for the formation of $1 \mathbf{a}_{3} \cdot(\mathrm{DEB})_{6} \cdot \mathbf{2} \mathbf{a}_{3}$ gave a binding constant of $6.0 \times 10^{10} \mathrm{M}^{-3}$ (Figure 8 ). Formation of $\mathbf{1} \mathbf{a}_{3} \cdot(\mathrm{DEB})_{6} \cdot \mathbf{2} \mathbf{a}_{3}$ is strongly enthalpy driven $\left(\Delta H^{\circ}=-31.9 \pm 0.6 \mathrm{~kJ} \cdot \mathrm{mol}^{-1}\right)$. The observed negative enthalpy change likely occurs from favorable $\pi-\pi$ interactions with the rosette layers possibly reinforced by the hydrogenbonded network formed between the three $\mathbf{2 a}$ molecules. The adverse negative entropy $\left(T \Delta S^{\circ}=-17.8 \pm 0.8 \mathrm{~kJ} \cdot \mathrm{mol}^{-1}\right)$ arises possibly from the restrictions in translational and rotational freedom of the three $\mathbf{2 a}$ guest molecules.

An overview of the ITC results for the encapsulation of the anthraquinone derivatives $\mathbf{2} \mathbf{a}-\mathbf{h}$ by $\mathbf{1} \mathbf{a}_{3} \cdot(\mathrm{DEB})_{6}$ is presented in Table 1. The ITC data show that the presence of a hydroxyl group at the $\mathrm{Y}^{2}$-position (ring $\mathrm{A}$ ) and the absence of functionalities in the C-ring of the anthraquinone skeleton (2a, 2f, and $2 \mathrm{~g}$ ) result in strong binding $\left(K_{\mathrm{a}}=\sim 10^{10} \mathrm{M}^{-3}\right)$. Only small differences were observed for the binding enthalpy and entropy of complexes $1 \mathbf{a}_{3} \cdot(\mathrm{DEB})_{6} \cdot \mathbf{2 a}_{3}, \mathbf{1}_{3} \cdot(\mathrm{DEB})_{6} \cdot \mathbf{2} \mathbf{f}_{3}$, and $\mathbf{1} \mathbf{a}_{3} \cdot(\mathrm{DEB})_{6} \cdot$ $\mathbf{2} \mathbf{g}_{3}$. The main structural difference between guest molecules $\mathbf{2 a}, \mathbf{2} \mathbf{f}$, and $\mathbf{2} \mathbf{g}$ is the number of hydroxyl groups present at the C-ring ( $\mathrm{Y}^{1}-, \mathrm{Y}^{2}$-, and $\mathrm{Y}^{4}$-positions; Table 1). The hydroxyl group at the $\mathrm{Y}^{2}$-position of these guests is responsible for the formation of the intermolecular hydrogen bonds between the guest trimer.
The hydroxyl groups at $\mathrm{Y}^{1}$ - and $\mathrm{Y}^{4}$-positions, which form intramolecular hydrogen bonds with the carbonyl moieties, do not affect the complexation since only relatively small differences in complexation were observed.

ITC measurements with 2d, having four hydroxyl groups, and $1 \mathbf{a}_{3} \cdot(\mathrm{DEB})_{6}$ did not show any appreciable heat effects, indicative of no complexation. As concluded from ${ }^{1} \mathrm{H}$ NMR studies, $\mathbf{1 a} \mathbf{a}_{3} \cdot(\mathrm{DEB})_{6}$ does not complex $\mathbf{2 d}$ because upon encapsulation one of the hydroxyl groups would have to occupy one of the forbidden areas in the receptor cavity (area $i$ or $i i$ in Figure 6).

Guest molecules $\mathbf{2 b}, \mathbf{2 c}$, and 2e, lacking the hydroxyl group at the $\mathrm{Y}^{2}$-position, but with a hydroxyl at the $\mathrm{Y}^{1}$-position, showed appreciable heat effects in the ITC measurements. Binding of these guest molecules to $\mathbf{1 a}_{3} \cdot(\mathrm{DEB})_{6}$ is, however, less efficient $\left(K_{\mathrm{a}} \sim 10^{6}-10^{8} \mathrm{M}^{-3}\right)$ than binding of $\mathbf{2 a}, \mathbf{2 f}$, and 2g. It seems that the absence of the intermolecular hydrogen bonds among the guest molecules decreases the binding affinity. ${ }^{40}$ Because many factors can contribute to the binding enthalpy and entropy of these complexes, it is difficult to attribute either to specific binding properties, but a few conclusions can be drawn.

The lower binding affinity of $\mathbf{2 e}$ for $\mathbf{1} \mathbf{a}_{3} \cdot(\mathrm{DEB})_{6}$ compared to that of $\mathbf{2 a}, \mathbf{2} \mathbf{f}$, and $\mathbf{2 g}$ is mainly due to lower binding enthalpy (Table 1) caused by the absence of an intermolecular hydrogenbonded network between the guest molecules. The entropy change for complex $\mathbf{1} \mathbf{a}_{3} \cdot(\mathrm{DEB})_{6} \cdot \mathbf{2}_{3}\left(T \Delta S^{\circ}=-13.3 \pm 0.4\right.$ $\left.\mathrm{kcal} \cdot \mathrm{mol}^{-1}\right)$ is comparable with that observed for the complexation between $\mathbf{1} \mathbf{a}_{3} \cdot(\mathrm{DEB})_{6}$ and $\mathbf{2 a}, \mathbf{2} \mathbf{f}$, and $\mathbf{2 g}$.

On the other hand, when comparing the binding affinities of $\mathbf{2 b}$ and $\mathbf{2 c}$ with $\mathbf{2 a}, \mathbf{2} \mathbf{f}$, and $\mathbf{2 g}$, the differences in the complex formation are mainly caused by differences in the binding entropy (Table 1), possibly because the position of the hydroxyl group at the C-ring leads to a decreased freedom of movement of the guests $\mathbf{2 b}$ and $\mathbf{2 c}$ in the calix[4]arene cone. However, although no intermolecular hydrogen-bonded network can be formed, the enthalpy values for encapsulation of $\mathbf{2 b}$ and $\mathbf{2 c}$ are comparable to those obtained for the complexation of $\mathbf{2 a}, \mathbf{2} \mathbf{f}$, and $\mathbf{2 g}$. ${ }^{40}$ Thus, enthalpy contributions different from the enthalpy of formation of the intermolecular hydrogen bonds have to be responsible for the larger $\Delta H^{\circ}$ values. It is, however, unclear which enthalpic contributions could explain these larger $\Delta H^{\circ}$ values. Differences in $\pi-\pi$ interactions due to different electron densities of the B-ring of $\mathbf{2} \mathbf{b}$ and $\mathbf{2} \mathbf{c}$ might play a role.

ITC measurements with $\mathbf{2 a}$ and assembly $\mathbf{1 a}_{3} \cdot(\mathrm{BuCYA})_{6}$ (with BuCYA instead of DEB; see Chart 1) did not show any appreciable heat effect, demonstrating that complex $\mathbf{1 a}_{3}$. $(\mathrm{BuCYA})_{6} \cdot \mathbf{2} \mathbf{a}_{3}$ is not formed. Probably small geometrical differences between $\mathbf{1} \mathbf{a}_{3} \cdot(\mathrm{DEB})_{6}$ and $\mathbf{1} \mathbf{a}_{3} \cdot(\mathrm{BuCYA})_{6}$ account for the inability of $\mathbf{1}_{3} \cdot(\text { BuCYA })_{6}$ to complex 2a. Molecular modeling (Quanta 97, CHARMm 24.0) indicated that the two rosette floors of $1 \mathbf{a}_{3} \cdot(\mathrm{BuCYA})_{6}$ are stacked on top of each other, with an interatomic separation of $3.2 \AA$ at the edges and $2.8 \AA$ in the center of the rosette, while for $\mathbf{1 a}_{3} \cdot(\mathrm{DEB})_{6}$, these interatomic separations are 3.5 and $3.2 \AA$. Possibly, additional stabilizing interactions between the rosette layers in $\mathbf{1 a}_{3}$. $(\text { BuCYA })_{6}$ might prevent encapsulation of $\mathbf{2 a} .^{43}$

(43) Another reason for the absence of complex formation might be the inability of the double rosette $1 \mathbf{a}_{3} \cdot(\mathrm{BuCYA})_{6}$ to form the assembly in the parallel orientation required for guest complexation. 
Table 1. ITC Data for the Complexation of the Anthraquinone Derivatives $\mathbf{2} \mathbf{a}-\mathbf{h}$ by the Molecular Box $1 \mathbf{a}_{3} \cdot(\mathrm{DEB})_{6}\left(\mathrm{Y}^{3}=\mathrm{Y}^{7}=\mathrm{H}\right.$, measurements were performed in 1,2-DCE at $298 \mathrm{~K}$ )

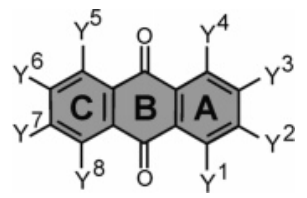

\begin{tabular}{|c|c|c|c|c|c|c|c|c|c|c|}
\hline guest & $Y^{1}$ & $\mathrm{Y}^{2}$ & $\mathrm{Y}^{4}$ & $Y^{5}$ & $Y^{6}$ & $\mathrm{Y}^{8}$ & $\begin{array}{c}K_{\mathrm{a}} \\
\left(\mathrm{m}^{-3}\right)\end{array}$ & $\begin{array}{c}\Delta H^{\circ} \\
\left(\mathrm{kcal} \cdot \mathrm{mol}^{-1}\right)\end{array}$ & $\begin{array}{c}\Delta G^{\circ} \\
\left(\mathrm{kcal} \cdot \mathrm{mol}^{-1}\right)\end{array}$ & $\begin{array}{c}T \Delta S^{\circ} \\
\left(\mathrm{kcal} \cdot \mathrm{mol}^{-1}\right)\end{array}$ \\
\hline $2 \mathbf{a}$ & $\mathrm{OH}$ & $\mathrm{OH}$ & $\mathrm{H}$ & $\mathrm{H}$ & $\mathrm{H}$ & $\mathrm{H}$ & $\begin{array}{l}(2.5 \pm 1.5) \times 10^{10} \\
(1.8 \pm 0.7) \times 10^{9 b}\end{array}$ & $-31.9 \pm 0.6$ & $-14.1 \pm 0.4$ & $-17.8 \pm 0.8$ \\
\hline $2 \mathbf{a}^{a}$ & $\mathrm{OH}$ & $\mathrm{OH}$ & $\mathrm{H}$ & $\mathrm{H}$ & $\mathrm{H}$ & $\mathrm{H}$ & & no heat & & \\
\hline $2 b$ & $\mathrm{OH}$ & $\mathrm{H}$ & $\mathrm{H}$ & $\mathrm{OH}$ & $\mathrm{H}$ & $\mathrm{H}$ & $(1.1 \pm 0.6) \times 10^{8}$ & $-31.2 \pm 1.1$ & $-10.9 \pm 0.3$ & $-20.3 \pm 1.0$ \\
\hline $2 c$ & $\mathrm{OH}$ & $\mathrm{H}$ & $\mathrm{H}$ & $\mathrm{H}$ & $\mathrm{H}$ & $\mathrm{OH}$ & $(2.5 \pm 0.2) \times 10^{7}$ & $-30.2 \pm 0.2$ & $-10.1 \pm 0.1$ & $-20.1 \pm 0.2$ \\
\hline 2d & $\mathrm{OH}$ & $\mathrm{OH}$ & $\mathrm{H}$ & $\mathrm{OH}$ & $\mathrm{H}$ & $\mathrm{OH}$ & - & no heat & & \\
\hline $2 e$ & $\mathrm{OH}$ & $\mathrm{H}$ & $\mathrm{H}$ & $\mathrm{H}$ & $\mathrm{H}$ & $\mathrm{H}$ & $\begin{array}{l}(3.6 \pm 1.9) \times 10^{6} \\
(6.8 \pm 2.8) \times 10^{5 b}\end{array}$ & $-22.2 \pm 0.8$ & $-8.9 \pm 0.3$ & $-13.3 \pm 0.4$ \\
\hline $2 f$ & $\mathrm{H}$ & $\mathrm{OH}$ & $\mathrm{H}$ & $\mathrm{H}$ & $\mathrm{H}$ & $\mathrm{H}$ & $\begin{array}{l}(4.1 \pm 2.0) \times 10^{10} \\
(1.0 \pm 0.1) \times 10^{9 b}\end{array}$ & $-28.7 \pm 0.8$ & $-14.4 \pm 0.3$ & $-14.2 \pm 0.8$ \\
\hline $2 \mathrm{~g}$ & $\mathrm{OH}$ & $\mathrm{OH}$ & $\mathrm{OH}$ & $\mathrm{H}$ & $\mathrm{H}$ & $\mathrm{H}$ & $(1.5 \pm 0.9) \times 10^{11}$ & $-30.3 \pm 1.7$ & $-15.2 \pm 0.4$ & $-15.2 \pm 2.1$ \\
\hline $2 \mathrm{~h}$ & $\mathrm{H}$ & $\mathrm{H}$ & $\mathrm{H}$ & $\mathrm{H}$ & $\mathrm{H}$ & $\mathrm{H}$ & & no heat & & \\
\hline
\end{tabular}

${ }^{a}$ Host $=1 \mathbf{a}_{3} \cdot(\mathrm{BuCYA})_{6} \cdot{ }^{b}$ Data from UV-vis titrations.

UV-Vis Spectroscopy. Anthraquinone derivatives are used as coloring agents, thus UV-vis spectroscopy can also be used to determine binding constants of the anthraquinone derivatives 2 to assembly $1 \mathbf{a}_{3} \cdot(\mathrm{DEB})_{6}$ in a simple way. Anthraquinone derivatives $\mathbf{2 a}, \mathbf{2} \mathbf{d}, \mathbf{2} \mathbf{e}$, and $\mathbf{2} \mathbf{f}$ were selected for the $\mathrm{UV}-\mathrm{vis}$ spectroscopy studies in 1,2-DCE.

The binding affinity of $\mathbf{2 a}$ for assembly $\mathbf{1 a}_{3} \cdot(\mathrm{DEB})_{6}$ was determined by titration experiments in 1,2-DCE (Table 1), and the changes in the absorbance at 432,500 , and $520 \mathrm{~nm}$ were monitored while aliquots of $\mathbf{2 a}(0-5.7$ equiv) were added to $\mathbf{1 a}_{3} \cdot(\mathrm{DEB})_{6}(0.5 \mathrm{mM})$. At these wavelengths, $\mathbf{1 a}_{3} \cdot(\mathrm{DEB})_{6}$ does not absorb and the absorbance of $\mathbf{2} \mathbf{a}$ is very small $\left(\epsilon_{\text {complex }} \gg\right.$ $\left.\epsilon_{\mathbf{2 a}}\right)$. The resulting binding isotherm was fitted to a 1:3 binding algorithm to yield a binding constant of $1.8 \times 10^{9} \mathrm{M}^{-3}$. Similar titration experiments were used to determine the binding constants of $2 \mathbf{e}(0.5 \mathrm{mM}$ assembly and $0-40$ equiv of $\mathbf{2 e})$ and $2 \mathbf{f}(0.64 \mathrm{mM}$ assembly and $0-5.7$ equiv of $\mathbf{2 f})$ in $1,2-\mathrm{DCE}$ (Table 1). Consistent with the ITC measurements, the association constant for $2 \mathrm{e}\left(K_{\mathrm{a}}=6.9 \times 10^{5} \mathrm{M}^{-3}\right)$ is about three decades lower than for $\mathbf{2 a}\left(K_{\mathrm{a}}=1.8 \times 10^{9} \mathrm{M}^{-3}\right)$, and the association constant of $2 \mathbf{f}\left(K_{\mathrm{a}}=1.0 \times 10^{9} \mathrm{M}^{-3}\right)$ is similar to the one found for $\mathbf{2 a}$. The UV-vis experiments with $\mathbf{2 d}$ did not show the encapsulation of this guest in $\mathbf{1 a}_{3} \cdot(\mathrm{DEB})_{6}$, as it was also proven by ITC and ${ }^{1} \mathrm{H}$ NMR spectroscopy. Thus, UV-vis spectroscopy showed to be a good alternative for ${ }^{1} \mathrm{H}$ NMR spectroscopy to determine the binding constants of anthraquinone derivatives. Nevertheless, determination of the thermodynamic data by direct measurement of the heat effects using ITC measurements is more suited than the indirect measure of the heat effect by combination of UV-vis spectroscopy and van't Hoff plots.

\section{Complexation by Chiral Receptors}

The effect of a chiral environment on the encapsulation of alizarin $\mathbf{2 a}$ by chiral rosettes $\mathbf{3 a}-\mathbf{b}_{3} \cdot(\mathrm{DEB})_{6}$ (Chart 1$)$, containing either an $(R)$-1-phenylethyl (3a) or an $(S)$-1-phenylethyl group (3b), has also been studied. Double rosette assembly $\mathbf{1 a}_{3}$. $(\mathrm{DEB})_{6}$ in the staggered conformation $\left(D_{3}\right.$ symmetry) displays supramolecular chirality, ${ }^{44}$ caused by the antiparallel orientation of the two melamine units in each calix[4]arene, which can be oriented either clockwise $(P)$ or counterclockwise $(M)$. In the absence of any other source of chirality, assembly $\mathbf{1 a}_{3} \cdot(\mathrm{DEB})_{6}$ exists as a racemic mixture of the $(P)$ and $(M)$ enantiomeric assemblies. Introduction of chiral substituents at one of the building blocks of the rosette leads to the formation of diastereomeric helices.

Both rosette assemblies $\mathbf{3 a}_{3} \cdot(\mathrm{DEB})_{6}$ and $\mathbf{3 b}_{3} \cdot(\mathrm{DEB})_{6}$ form quantitatively in chloroform, toluene, and benzene, as could be confirmed by ${ }^{1} \mathrm{H}$ NMR spectroscopy. The presence of only two signals in the 15-13 ppm region (instead of four as expected for the diastereomeric mixture) indicates that both double rosettes are present exclusively as one of the two possible diastereomers (complete chiral induction). Assembly $\mathbf{3} \mathbf{a}_{3} \cdot(\mathrm{DEB})_{6}$ exists only in the $(M)$ configuration and assembly $\mathbf{3 b}_{3} \cdot(\mathrm{DEB})_{6}$ only in the $(P)$ configuration. Therefore, due to the fact that dimelamine derivatives $\mathbf{3 a}$ and $\mathbf{3 b}$ are enantiomers, the two assemblies $(M)-\mathbf{3} \mathbf{a}_{3} \cdot(\mathrm{DEB})_{6}$ and $(P)-\mathbf{3} \mathbf{b}_{3} \cdot(\mathrm{DEB})_{6}$ are also enantiomers.

Upon addition of $\mathbf{2 a}$ (3-4 equiv) to either $(M)-\mathbf{3} \mathbf{a}_{3} \cdot(\mathrm{DEB})_{6}$ or $(P)-3 \mathbf{b}_{3} \cdot(\mathrm{DEB})_{6}\left(1.0 \mathrm{mM}\right.$ in $\mathrm{CDCl}_{3}$ at $\left.298 \mathrm{~K}\right)$, the initial two signals of the $\mathrm{NH}_{\mathrm{DEB}}$ protons between 12 and 15 ppm disappeared, and four new signals in this area appeared (Figure 9). The $\mathrm{NH}_{\text {DEB }}$ protons $\mathrm{H}_{\mathrm{a}}$ and $\mathrm{H}_{\mathrm{b}}$ resonate after complexation of 2a at 13.66, 13.42, 12.93, and 12.89 ppm. Additionally, a downfield shift of $3.79 \mathrm{ppm}$ was observed for the $\mathrm{OH}_{n}$ proton of 2a (Figure 9). Also, the changes in chemical shifts for the other protons of the guest $\mathbf{2} \mathbf{a}$ and the assemblies $\mathbf{3 a}, \mathbf{b}_{3} \cdot(\mathrm{DEB})_{6}$ are comparable to the shifts obtained for the protons in the complexation of $\mathbf{2} \mathbf{a}$ with the racemic assembly $\mathbf{1 a}_{3} \cdot(\mathrm{DEB})_{6}$.

The presence of four signals in the ${ }^{1} \mathrm{H}$ NMR spectrum indicates that the complexes $(M)$ - or $(P)-\mathbf{3}_{3} \cdot(\mathrm{DEB})_{6} \cdot \mathbf{2}_{3}$ have

(44) Prins, L. J.; Huskens, J.; De Jong, F.; Timmerman, P.; Reinhoudt, D. N. Nature 1999, 398, 498-502.

(45) (a) Sheldrick, G. M. SHELXL86. Program for Crystal Structure Solution University of Göttingen: Göttingen, Germany, 1986. (b) SHELXL97.

Program for Crystal Structure Refinement; University of Göttingen: Göttinger, Germany, 1997.

(46) Spek, A. L. J. Appl. Crystallogr. 2003, 36, 7-13. 


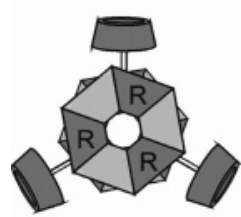

$3 \mathbf{a}_{3} \cdot(\mathrm{DEB})_{6}$

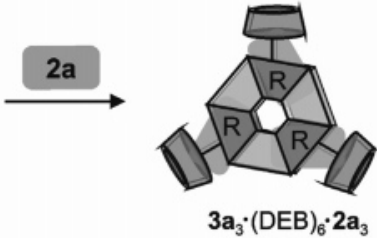

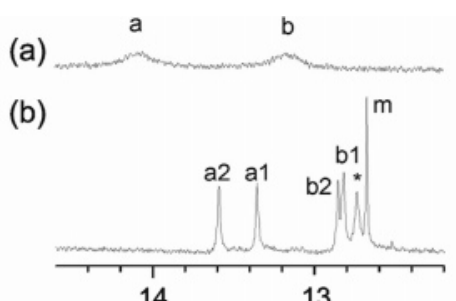

14

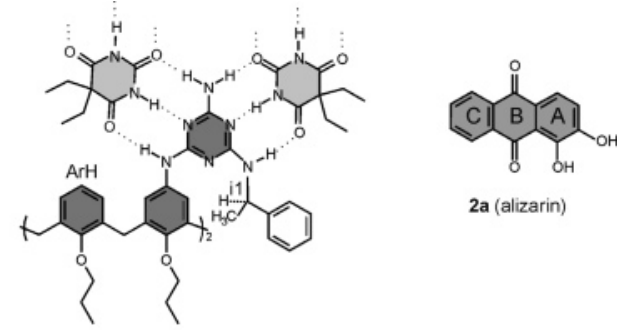

Figure 9. Part of the ${ }^{1} \mathrm{H}$ NMR spectra of (a) assembly $\mathbf{3} \mathbf{a}_{3} \cdot(\mathrm{DEB})_{6}$ and (b) complex $\mathbf{3} \mathbf{a}_{3} \cdot(\mathrm{DEB})_{6} \cdot \mathbf{2} \mathbf{a}_{3}$ (for similar proton assignment, see Figure 1 ). The signal marked with $*$ belongs to $\mathrm{OH}_{m}$ of free $\mathbf{2 a}$. Both spectra were recorded in $\mathrm{CDCl}_{3}$ at $300 \mathrm{MHz}$ at $298 \mathrm{~K}$.

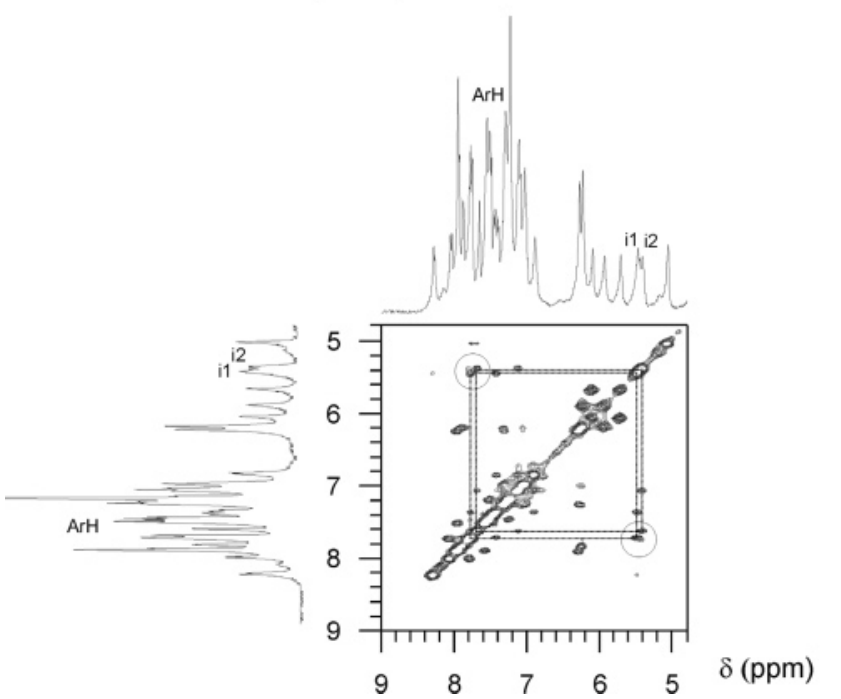

Figure 10. Part of the NOE spectrum of complex $(R)-\mathbf{3} \mathbf{a}_{3} \cdot(\mathrm{DEB})_{6} \cdot \mathbf{2}_{3}\left(\mathrm{H}_{i 2}\right.$ refers to the proton of the asymmetric carbon on the second floor of the assembly).

$C_{3}$ symmetry. However, the melamine units can adopt either a symmetrical eclipsed or staggered conformation, and therefore, no discrimination between these two complexes can be made based on the number of signals observed in the ${ }^{1} \mathrm{H}$ NMR spectrum. Thus, 2D ${ }^{1} \mathrm{H}$ NMR spectroscopy studies were carried out. NOE connectivities were observed between "chiral" proton $\mathrm{H}_{i 1}$ and the protons of one calix[4]arene aromatic rings without melamine substituents (ArH) (Figure 11). The corresponding proton on the second rosette floor $\left(\mathrm{H}_{i 2}\right)$ showed NOE connectivities with the same aromatic ring, which is only possible for the symmetrical eclipsed conformation of the assembly. Thus, encapsulation of $\mathbf{2} \mathbf{a}$ changed the symmetry of the complex from $D_{3}$ to $C_{3}$.

Furthermore, as it has been mentioned before, the introduction of chiral centers in the building blocks leads to the formation of diastereomerically pure assemblies $(M)-3 \mathbf{a}_{3} \cdot(\mathrm{DEB})_{6}$ and $(P)$ $\mathbf{3 b}_{3} \cdot(\mathrm{DEB})_{6}$, which are highly circular dichroism (CD) active due to the asymmetric rearrangement of the different chromophores within the rigid structure. Thus, this technique is of tremendous value in the characterization of these complexes.

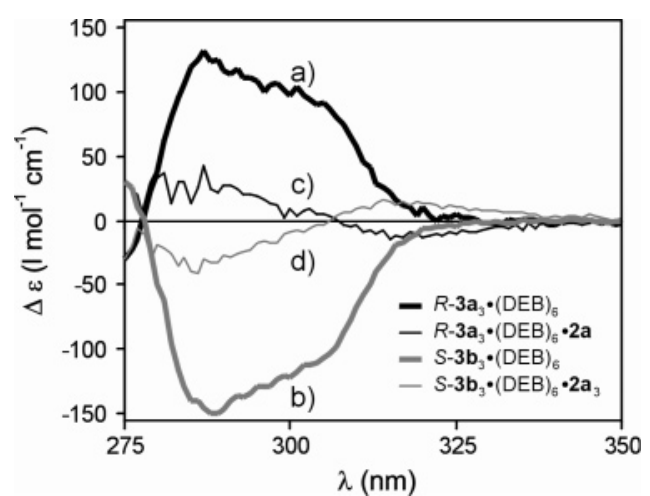

Figure 11. $\mathrm{CD}$ spectra of assemblies $\mathbf{3 a}, \mathbf{b}_{3} \cdot(\mathrm{DEB})_{6}$ before (a and $\left.\mathrm{b}\right)$ and after (c and d) addition of 4 equiv of 2a. All spectra were recorded in benzene- $d_{6}(1.0 \mathrm{mM}$ for the assemblies) at $298 \mathrm{~K}$.

Intriguingly, the CD signal of both assemblies is almost silent after addition of 4 equiv of $\mathbf{2 a}$ (Figure 11). The observed decrease in $\mathrm{CD}$ intensity is not due to the destruction of the assemblies because ${ }^{1} \mathrm{H}$ NMR spectroscopy showed by integration of the $\mathrm{NH}_{\text {DEB }}$ protons that the assemblies were still quantitatively present after alizarin complexation. Additionally, racemization is also ruled out because total induction for complexes $\mathbf{3}_{3} \cdot(\mathrm{DEB})_{6} \cdot \mathbf{2} \mathbf{a}_{3}$ is proven by ${ }^{1} \mathrm{H}$ NMR spectroscopy (only one set of four different signals). Furthermore, the ${ }^{1} \mathrm{H}$ NMR spectra of assemblies $(M)-\mathbf{3} \mathbf{a}_{3} \cdot(\mathrm{DEB})_{6} \cdot \mathbf{2} \mathbf{a}_{3}$ and $(P)-\mathbf{3} \mathbf{b}_{3} \cdot$ $(\mathrm{DEB})_{6} \cdot \mathbf{2} \mathbf{a}_{3}$ are identical, indicating that the two complexes are indeed enantiomers. Thus, the decrease of the $\mathrm{CD}$ intensity upon encapsulation of $\mathbf{2} \mathbf{a}$ should be due to the symmetry change from the helical staggered to the nonhelical (symmetrical) eclipsed.

The decrease in the CD intensity of the signal can be used to determine the binding affinity of $\mathbf{2 a}$ to assembly $(M)-\mathbf{3} \mathbf{a}_{3} \cdot(\mathrm{DEB})_{6}$ or $(P)-3 \mathbf{b}_{3} \cdot(\mathrm{DEB})_{6}\left(1 \mathrm{mM}\right.$ in either $\mathrm{CHCl}_{3}$ or benzene- $\left.d_{6}\right)$. A binding constant $\left(K_{\mathrm{a}}\right)$ of $1.1 \times 10^{12} \mathrm{M}^{-3}$ for $\mathbf{2 a}$ to assembly $(M)-3 \mathbf{a}_{3} \cdot(\mathrm{DEB})_{6}$ in $\mathrm{CHCl}_{3}$ was estimated using the same binding model as for the encapsulation of $\mathbf{2} \mathbf{a}$ by the racemic assembly $1 \mathbf{a}_{3} \cdot(\mathrm{DEB})_{6}$ (formation of the complex in one step). In a similar experiment, a $K_{\mathrm{a}}$ of $7.5 \times 10^{10} \mathrm{M}^{-3}$ for the encapsulation of $\mathbf{2 a}$ by assembly $(P)-\mathbf{3 b}_{3} \cdot(\mathrm{DEB})_{6}$ in $\mathrm{CHCl}_{3}$ was calculated. In benzene- $d_{6}, K_{\mathrm{a}}$ values of the same order of magnitude were observed.

In summary, encapsulation of alizarin by chiral receptors occurs in a similar manner as the complexation by racemic receptors; that is, three molecules of the guest are encapsulated between the rosette floors, resulting in a change of symmetry from $D_{3}$ to $C_{3}$.

\section{Conclusions}

It has been shown that a series of anthraquinone derivatives $(\mathbf{2 a}-\mathbf{h})$ form hydrogen-bonded trimers by encapsulation be- 
tween the two rosette layers of the noncovalent hydrogen-bonded receptor $\mathbf{1 a}_{3} \cdot(\mathrm{DEB})_{6}$. This encapsulation process enforces large structural changes in the assembly, resulting in a complete change of symmetry from staggered to eclipsed and in an enlargement of the cavity of the molecular box in the solid state as well as in solution. Combination of X-ray crystallography, ${ }^{1} \mathrm{H}$ NMR spectroscopy, ITC, and UV spectroscopy allowed the identification of the different modes of guest complexation. The driving force for the encapsulation is presumably $\pi-\pi$ stacking between the electron-poor center ring of the anthraquinone derivatives and the relatively electron-poor melamine units of the receptor $\mathbf{1 a}_{3} \cdot(\mathrm{DEB})_{6}$. The encapsulation of anthraquinone derivatives by the receptor is very selective and sensitive to small structural changes. To achieve complexation, the $\mathrm{Y}^{6}$ - and/ or $\mathrm{Y}^{8}$-positions at ring $\mathrm{C}$ of the anthraquinone skeleton should be unsubstituted. Furthermore, functionalities situated adjacent to these positions decrease the binding affinity, probably because of the decreased freedom of the guests in the calix[4]arene cone (entropic penalty). Anthraquinone derivatives with a hydroxyl group at the $\mathrm{Y}^{2}$-position (ring $\mathrm{A}$ ) and without functionalities in the $\mathrm{C}$-ring have the highest binding affinity due to the formation of an intermolecular hydrogen-bonded network between adjacent guest molecules and to the absence of steric interference between ring $\mathrm{C}$ and the calix[4]arene cone. There is no steric hindrance observed when hydroxyl groups are present at any position of ring $\mathrm{A}$ of these anthraquinone derivatives. A similar encapsulation mode for the chiral noncovalent containers $\mathbf{3}_{3} \cdot(\mathrm{DEB})_{6}$ as for the racemic $\mathbf{1 a}_{3} \cdot(\mathrm{DEB})_{6}$ was observed.

Acknowledgment. This work is partially supported by the Technology Foundation of The Netherlands (J.M.C.A.K. and M.G.J.T.C.) and the Council for the Chemical Sciences of The Netherlands Organization for Scientific Research (A.L.S.). The research of M.C.-C. has been made possible by a fellowship of the Royal Netherlands Academy of Arts and Sciences.

Supporting Information Available: Molecular mechanics calculations, full X-ray crystal structures, and detailed experimental procedures. This material is available free of charge via the Internet at http://pubs.acs.org.

JA0536973 